\title{
Improved High Temperature Stability of Anatase TiO2 Photocatalysts by N, F, P co-doping
}

\author{
Rachel Fagan \\ Technological University Dublin, rachel.fagan@mydit.ie \\ Declan Mccormack \\ Technological University Dublin, Declan.mccormack@tudublin.ie \\ Steven Hinder \\ University of Surrey
}

See next page for additional authors

Follow this and additional works at: https://arrow.tudublin.ie/scschcpsart

Part of the Analytical Chemistry Commons, Materials Chemistry Commons, and the Physical Chemistry Commons

\section{Recommended Citation}

Fagan, R. et al. (2016) Improved High Temperature Stability of Anatase TiO2 Photocatalysts by N, F, P codoping, Materials \& Design, Vol. 96, 15 April, 2016, p. 44-53. doi.10.1016/j.matdes.2016.01.142

This Article is brought to you for free and open access by the School of Chemical and Pharmaceutical Sciences at ARROW@TU Dublin. It has been accepted for inclusion in Articles by an authorized administrator of ARROW@TU

Dublin. For more information, please contact

arrow.admin@tudublin.ie, aisling.coyne@tudublin.ie, gerard.connolly@tudublin.ie.

Funder: Science Foundation Ireland

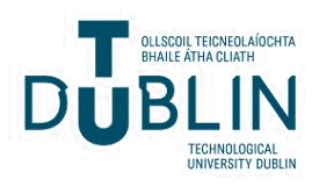




\section{Authors}

Rachel Fagan, Declan Mccormack, Steven Hinder, and Suresh Pillai

This article is available at ARROW@TU Dublin: https://arrow.tudublin.ie/scschcpsart/53 


\section{Improved High Temperature Stability of Anatase $\mathrm{TiO}_{2}$ Photocatalysts by N, F, P co-doping}

Rachel Fagan, Declan E. McCormack, Steven J. Hinder and Suresh C. Pillai

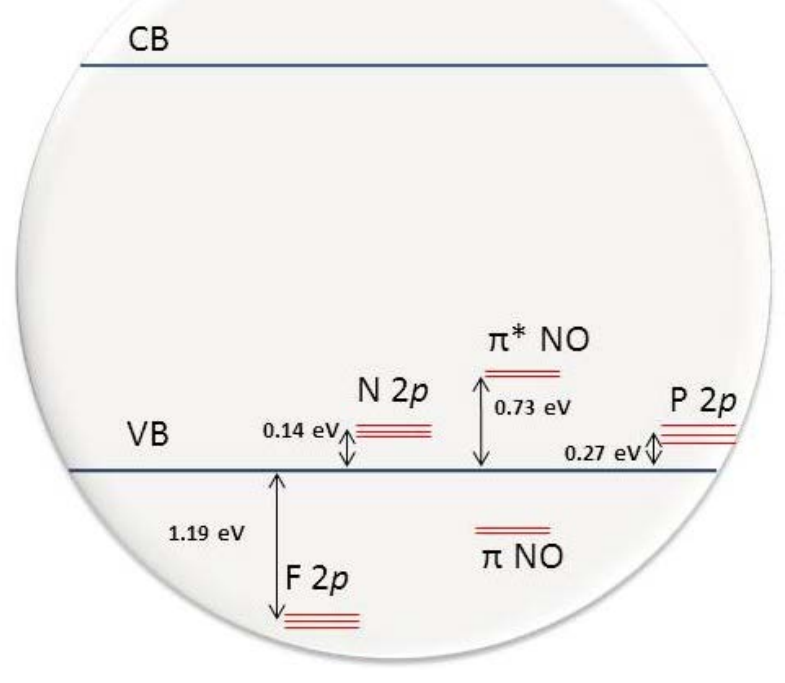




\title{
Improved High Temperature Stability of Anatase $\mathrm{TiO}_{2}$ Photocatalysts by N, F, P co-doping
}

\author{
Rachel Fagan, ${ }^{a, b}$ Declan E. McCormack, ${ }^{a, b^{*}}$ Steven J. Hinder, ${ }^{c}$ and Suresh C. Pillai, ${ }^{d, e^{*}}$ \\ ${ }^{a}$ Centre for Research in Engineering Surface Technology (CREST), FOCAS Institute, Dublin \\ Institute of Technology, Kevin St, Dublin 8, Ireland \\ ${ }^{\mathrm{b}}$ School of Chemical and Pharmaceutical Sciences, Dublin Institute of Technology, Kevin St., Dublin \\ 8, Ireland \\ ${ }^{\mathrm{c}}$ The Surface Analysis Laboratory, Department of Mechanical Engineering Sciences, University of \\ Surrey, Guildford, Surrey, GU2 7XH, United Kingdom \\ ${ }^{\mathrm{d}}$ Nanotechnology Research Group, Department of Environmental Sciences, Institute of Technology \\ Sligo, Ireland \\ ${ }^{\mathrm{e}}$ Centre for Precision Engineering, Materials and Manufacturing Research (PEM), Institute of \\ Technology Sligo, Sligo, Ireland. E mail Pillai.suresh@itsligo.ie
}

\begin{abstract}
Among the three commonly occurring phases (anatase, rutile, and brookite) of $\mathrm{TiO}_{2}$, the anatase form is reported to be the best photocatalyst due to the improved charge-carrier mobility and the greater number of surface hydroxyl groups. The anatase to rutile transition in titania photocatalysts usually occurs at a temperature between $500{ }^{\circ} \mathrm{C}$ to $700{ }^{\circ} \mathrm{C}$. Anatase, a well-known photocatalyst, typically converts to rutile between temperatures of $500{ }^{\circ} \mathrm{C}$ to $700{ }^{\circ} \mathrm{C}$. Development of a high temperature stable (above $1000{ }^{\circ} \mathrm{C}$ ) anatase phase is important for various environmental applications (e.g self-cleaning ceramic tiles, anti-microbial sanitary wares etc). In this study, the use of ammonium hexafluorophosphate as a single source dopant (method A) and urea, trifluoroacetic acid and phosphoric acid as multiple sources (method B) was undertaken in improving its high temperature stability. Method A was seen to produce a more stable anatase phase, with $68 \%$ anatase present at $1100{ }^{\circ} \mathrm{C}$, compared to method B which showed $100 \%$ rutile at $900{ }^{\circ} \mathrm{C}$. Kinetic analysis shows a marked increase in the photocatalytic degradation of a model dye using materials calcined at $1100{ }^{\circ} \mathrm{C}$ for method $\mathrm{A}$ $\left(0.042 \mathrm{~min}^{-1}\right)$ compared to that for method B $\left(0.005 \mathrm{~min}^{-1}\right)$ and the commercial photocatalyst Evonik-Degussa AEROXIDE ${ }^{\circledR}\left(0.031 \mathrm{~min}^{-1}\right)$ at $1100{ }^{\circ} \mathrm{C}$ XPS results showed that, the only dopant detected at high temperatures is phosphorus in its $\mathrm{P}^{5+}$ form. The incorporation of phosphorus has proved to be an effective method in stabilising the anatase phase at high temperature. The current investigation also showed that a single source precursor is more favourable to obtain high temperature stable anatase phase photocatalysts.
\end{abstract}

\section{Introduction}

The unique properties of $\mathrm{TiO}_{2}$ have attracted enormous attention over the past thirty years in energy and environmental sciences [1-7]. It is used in various applications such as self-cleaning [8,9], sterilization [10], anti-fogging [11], lithography [12], degradation of organic compounds [13-15] and metal corrosion prevention [16]. The anatase phase of titanium dioxide is known to be a better performing photocatalyst compared to brookite or rutile phase because of its improved charge-carrier mobility and the higher number of surface hydroxyl groups [17]. Stoichiometric anatase titania is active in the near-UV, limiting its utility to environments with a significant ultraviolet light flux. It is chemically and photo-chemically stable, but is normally only excited by ultraviolet light $(\lambda<390 \mathrm{~nm})$ so that the light utilization

efficiency to solar irradiation and a fluorescent lamp is very low [18]. Therefore, attempts were made to extend the absorption range of titanium dioxide into the visiblelight region [19]. Some methods used to improve the 
efficiency of $\mathrm{TiO}_{2}$ are impurity doping, sensitisation [20], surface modification [21,22], and fabrication of composites with other materials [23]. Modified $\mathrm{TiO}_{2}$ can differ from standard $\mathrm{TiO}_{2}$ in several ways including light absorption, charge recombination dynamics, surface structure and charge, interfacial charge transfer kinetics, and adsorption of substrates [23]. Firstly, the role of the dopants in forming the resulting material needs to be considered. The use of cations (metals) in the doping of $\mathrm{TiO}_{2}$ was avoided due to their tendency to increase charge carrier recombination centers [24], and the generation of secondary impurity phases which inevitably reduces the photo-activity of titania [25]. It is also suggested that despite the decrease in band gap energy, the metals were not successfully introduced into the $\mathrm{TiO}_{2}$ framework, and that the remaining metals on the outside surface sheltered the photo-reaction sites [26]. Significant attention has been directed at reducing the band gap by doping with a range of elements including nitrogen [27-29], carbon [25,30], sulphur [31,32], phosphorus [33,34], and fluorine [35,36]. There have been several attempts at producing hightemperature stable anatase $[31,37,38]$. The importance of this is its applications in several industries, most notably in the production of ceramic materials (e.g. wall tiles) which retain an antibacterial property [39]. Additional areas which have been identified as benefitting from a high temperature stable form of anatase are sanitary wares and self-cleaning glass. All these require the use of very high temperatures during their processing stages and therefore a stable anatase phase at the sintering temperature is a necessity [40].

The current investigation seeks to determine the influence of the doping (the term "doping" is used loosely for describing the addition of N, P and F into the lattice, surface or interstitial sites) on the production of high temperature stable titanium dioxide. A number of questions arise which prompted this investigation. Is there a difference in the properties of the samples when incorporated by a single-step reaction or a multiple step reaction? Can these properties be clearly defined? Which procedure provides the best method of doping titania? These questions prompted the comparison of doping methods which are studied in this paper. Single step doping refers to the doping of the titania from a single source precursor which yields multiple dopants. For example, ammonium hexafluorophosphate is used as a source of nitrogen, fluorine and phosphorus. Multiple step doping refers to the introduction of dopants individually, i.e. urea (nitrogen), trifluoroacetic acid (fluorine) and phosphoric acid (phosphorus) into one system. The effectiveness of the doping method on the particle size, phase composition and the band gap reduction for visible light activation was studied along with the interaction properties between the titania and the dopants. Dopants such as nitrogen, fluorine and phosphorus have been chosen in this particular study with each element providing specific advantages Nitrogen can be used as a dopant in the alteration of the band-gap of $\mathrm{TiO}_{2}$ introducing filled $\mathrm{N} 2 p$ states above the $\mathrm{TiO}_{2}$ valence band [1]. Fluorine doping is also effective in causing modifications of the electronic structure of $\mathrm{TiO}_{2}$ by the formation of surface oxygen vacancies due to charge compensation between $\mathrm{F}^{-}$and $\mathrm{Ti}^{4+}$ but without creating a substantial variation in the optical absorption of $\mathrm{TiO}_{2}$ [33]. F-doping is understood to not only retard the anatase to rutile transition, but causes an increase in the concentration of ${ }^{\circ} \mathrm{OH}$ radicals in solution, improving the photo-degradation rate of organic compounds [36,41]. Phosphorus is another dopant of interest as it could be used to stabilise the $\mathrm{TiO}_{2}$ porous framework and increase the photocatalytic activity effectively [24,42].

A simple method of preparation is used involving the modification of a precursor, titanium tetraisopropoxide (TTIP), by the various dopants. Along with hydrolysis, microwave irradiation, drying and calcination were employed to produce various powdered samples. These were then characterised by X-ray diffraction (XRD), Raman, FT-IR and diffuse absorbance spectroscopy along with photocatalysis studies.

\section{Experimental}

\subsection{Materials}

In this study, titanium tetraisopropoxide (97.0 \%), isopropanol (99.0\%), ammonium hexafluorophosphate (NFP) ( $\geq 95.0 \%$ ), urea (N) ( $\geq 98.0 \%$ ), trifluoroacetic acid (TFA) (99.0\%) and phosphoric acid (PA) (85 wt.\%) were purchased from Aldrich and were used without further purification to prepare the samples. The dye used for the photocatalytic study (rhodamine 6G) was obtained from Eastman and was of analytical reagent grade and used without further purification. Deionised water was used in all experiments.

\subsection{Preparation of nanomaterials}

\subsubsection{Preparation of ammonium hexafluorophosphate added titanium dioxide by a 1 step procedure - Method A}

In a typical experiment to prepare a 1:0.5 molar ratio sample of titania (TTIP): dopant, $9.36 \mathrm{ml}$ (0.032 mol) of titanium isopropoxide $\left(\mathrm{Ti}(\mathrm{OPr})_{4}\right)$ was added slowly with stirring to $82.4 \mathrm{ml}(1.078 \mathrm{~mol})$ of isopropanol. To this solution, a mixture of $2.605 \mathrm{~g}(0.016 \mathrm{~mol})$ of ammonium 
hexafluorophosphate $\left(\mathrm{NH}_{4} \mathrm{PF}_{6}\right)$ in $120 \mathrm{ml}(6.659 \mathrm{~mol})$ of deionised water was added drop wise. The precipitate was stirred for 2 hours at room temperature. The resulting solution was then irradiated in a CEM MARS 5 microwave system under ambient pressure at 400 watts for 20 minutes. The irradiated precipitate was then filtered and the solid obtained was washed with $100 \mathrm{ml}$ of deionised water. The resulting solid was placed in an oven at $80^{\circ} \mathrm{C}$ to dry. The dried powder was calcined at $100{ }^{\circ} \mathrm{C}$ intervals ranging from $400-1000{ }^{\circ} \mathrm{C}$ with a ramp rate of $5^{\circ} \mathrm{C} / \mathrm{min}$ and held at these temperatures for a 2 hour period. This method of preparation will be further referred to as method A, with samples denoted as NFP$\mathrm{X}$, with $\mathrm{X}$ being the ratio of dopant present. Associated calcination temperatures are given.

\subsubsection{Preparation of titanium dioxide with multiple dopants by a 3 step procedure - Method B}

In a typical experiment to prepare a 1: 0.5 titania: dopant sample, $18.72 \mathrm{ml}(0.064 \mathrm{~mol})$ of titanium isopropoxide $\left(\mathrm{Ti}(\mathrm{OPr})_{4}\right)$ was added slowly with stirring to $164.8 \mathrm{ml}$ ( $2.156 \mathrm{~mol}$ ) of isopropanol. To this solution, a mixture of $1.92 \mathrm{~g}(0.032 \mathrm{~mol})$ of urea $\left(\mathrm{CH}_{4} \mathrm{~N}_{2} \mathrm{O}\right)$ in $240 \mathrm{ml}$ (13.318 mol) of deionised water was added drop wise to generate $\mathrm{N}$-doped $\mathrm{TiO}_{2}$. The precipitate was stirred for 2 hours at room temperature. The resulting solution was then irradiated in a CEM MARS 5 microwave system under ambient pressure at 400 watts for 20 minutes. 2.45 $\mathrm{ml}(0.032 \mathrm{~mol})$ of TFA was then added to the solution and left to stir for 2 hours followed by microwave irradiation at 400 watts for 20 minutes. Furthermore, $1.86 \mathrm{ml}(0.036 \mathrm{~mol})$ of phosphoric acid was added before final microwave irradiation (400 watts for 20 minutes). The resulting solid was placed in an oven at 80 ${ }^{\circ} \mathrm{C}$ to dry. The dried powder was calcined at $100{ }^{\circ} \mathrm{C}$ intervals ranging from $400-1000{ }^{\circ} \mathrm{C}$ with a ramp rate of $5{ }^{\circ} \mathrm{C} / \mathrm{min}$ and held at these temperatures for a 2 hour period. As above, this method of preparation will be further referred to as method $B$ with samples denoted as NFP-X, with $X$ being the ratio of dopant present. Associated calcination temperatures are given. In a similar procedure, individual dopants have also been produced using urea $\left(\mathrm{N}\right.$-doped $\left.\mathrm{TiO}_{2}\right)$, trifluoroacetic acid (F-doped $\mathrm{TiO}_{2}$ ) and phosphoric acid (P-doped $\mathrm{TiO}_{2}$ ).

\subsection{Characterisation}

A combination of analytical techniques was used allowing the full characterisation of the $\mathrm{N}, \mathrm{F}, \mathrm{P}-\mathrm{TiO}_{2}$ samples produced. These techniques included $\mathrm{X}$-ray diffraction using a Siemens $D 500$ X-ray diffractometer with the diffraction angles scanning from $2 \theta=20^{\circ}-80^{\circ}$, using a $\mathrm{Cu} \mathrm{K} \alpha$ radiation source. The crystallite size for each sample was calculated using the Scherrer equation (eq. 1) [43].

$$
\mathrm{D}=\frac{0.9 \lambda}{\beta \cos \theta}
$$

Where $\mathrm{D}=$ crystalline size, $\lambda=$ is the $\mathrm{x}$-ray radiation wavelength $(0.154 \mathrm{~nm}), \beta=$ is the full line width at halfmaximum height of the main intensity peak and $\theta=$ Bragg's angle.

XRD can also be used in order to calculate the percentage of anatase and rutile phases present in each sample analysed. This is measured using the Spurr equation (eq. 2) [44].

$$
\% \text { rutile }=\frac{1}{1+0.8\left[I_{A}(101) / I_{\mathrm{R}}(110)\right]}
$$

$I_{A}=$ is the intensity of (101) anatase peak.

$I_{R}=$ is the intensity of (110) rutile peak.

Raman spectroscopy carried out using a Horiba Jobin Yvon LabRAM HR system was used to confirm the crystalline phase present in the desired samples. Samples were analysed using the $50 \mathrm{x}$ objective lens at filter percentages between 1-100 \% which varied according to the intensity recorded for each samples. A 300 grating and a scan range of $0-1200 \mathrm{~cm}^{-1}$ was used in all experiments with each run having an exposure time of 3 seconds. The Spectrum GX-FTIR spectrophotometer was used to confirm the formation of $\mathrm{TiO}_{2}$ and the molecular interactions achieved with the dopants present, measured over a range of $400-4000 \mathrm{~cm}^{-1}$ with an accumulation of 8 scans. In order to study the optical properties, the diffuse absorbance spectra of solid powder samples were measured employing an integrating sphere in absorbance mode. For this analysis, a Perkin Elmer Lambda 900 UV-Vis absorption spectrophotometer was used, with scans ran over a range of 300 and $600 \mathrm{~nm}$. XPS analyses were performed on a Thermo VG Scientific (East Grinstead, UK) ESCALAB Mk II spectrometer. The instrument is equipped with an $\mathrm{XR3}$ twin anode $\mathrm{X}$-ray source $(\mathrm{A} 1 \mathrm{~K} \alpha / \mathrm{MgK} \alpha)$ and an Alpha 110 analyser. In this work the twin anodes AlK $\alpha$ $\mathrm{X}$-ray source $(\mathrm{h} v=1486.6 \mathrm{eV})$ was used at $300 \mathrm{~W}(15$ $\mathrm{kV}$ x $20 \mathrm{~mA}$ ) for all analyses. For all survey spectra a Pass Energy of $200 \mathrm{eV}$ and a step size of $0.4 \mathrm{eV}$ was employed. A Pass Energy of $20 \mathrm{eV}$ and a step size of 0.2 $\mathrm{eV}$ was used for the acquisition of $\mathrm{C} 1 s, \mathrm{O} 1 s$ and $\mathrm{Ti} 2 p$ high resolution spectra. A Pass Energy of $100 \mathrm{eV}$ and a step size of $0.2 \mathrm{eV}$ was used for the acquisition of F1s, $\mathrm{N} 1 s, \mathrm{P} 2 p, \mathrm{Si} 2 p, \mathrm{Al} 2 p$ and valence band high resolution spectra. All spectra were referenced against the C1s 
peak at $285 \mathrm{eV}$ to correct for charging effects during acquisition.

\subsection{Photocatalytic Study}

Photocatalysis studies were carried out with rhodamine 6G using simulated solar irradiation. These studies were carried out by varying parameters to examine to effect of the $\mathrm{TiO}_{2}$ samples on the above dye. These parameters were time, concentration of sample and concentration of dye. The results presented below are from using optimum conditions of dye concentration, sample concentration and irradiation time.

Photocatalysis studies were carried out using a Q-Sun solar simulator at $340 \mathrm{~nm}$ with a power output of 0.28 $\mathrm{W} / \mathrm{m}^{2} .25 \mathrm{mg}$ of each sample was added to $50 \mathrm{ml}$ of 8.62 $\mathrm{x} 10^{-6} \mathrm{M}$ of rhodamine $6 \mathrm{G}$. The above suspension was stirred for $30 \mathrm{~min}$ in the dark to equilibrate and eliminate any error due to the initial adsorption effect. Aliquots were taken at 10 minute intervals for a period of 60 minutes and then centrifuged for a period of $20 \mathrm{~min}$ to remove all solids remaining in solution to avoid any error due to scattering. These aliquots were then analysed using a UV-Vis spectrometer to measure their degradation properties. The catalytic efficiency was assumed to obey pseudo-first order kinetics and the rate constant for degradation, $k$, was calculated from the first order rate plot. Irradiation of rhodamine $6 G$ in the absence of a catalyst was conducted using the same steps as above. Analysis with a UV-Vis spectrometer showed no degradation of the dye was seen over time in the absence of the catalyst.

\section{Results}

\subsection{X-Ray Diffraction}

N, F and P doped samples from both methods were analysed for their phase compositions using XRD. Method A clearly produced the anatase phase which is identified in Fig. 1 below and is present at temperatures as high as $1000{ }^{\circ} \mathrm{C}$. At $500{ }^{\circ} \mathrm{C}$, the onset of formation of the anatase phase can be seen. As the temperatures increased in increments of $100{ }^{\circ} \mathrm{C}$, this phase is seen to develop and by $700{ }^{\circ} \mathrm{C}$, defined anatase peaks can be seen at 25.4, 38, 48 and $54^{\circ}$ (Supporting information Fig. S.1). Also visible in these results are other peaks which can be attributed to the formation of titanium oxide phosphate $\left((\mathrm{TiO})_{2} \mathrm{P}_{2} \mathrm{O}_{7}\right)$ and, to a lesser extent, titanium phosphate $\left(\mathrm{Ti}_{4} \mathrm{P}_{6} \mathrm{O}_{23}\right)$ alongside the anatase phase, supporting the later Raman results. In the lower temperature samples, 400 and $500{ }^{\circ} \mathrm{C}$, broad peaks in the region of 23.6 and $28^{\circ}$ are seen. As the temperature is increased, narrow peaks are formed. The main peaks are located at 24.4 and $27.2^{\circ}$, with smaller peaks at 44.9 and $62.8^{\circ}$ seen in all samples calcined above $700{ }^{\circ} \mathrm{C}$.

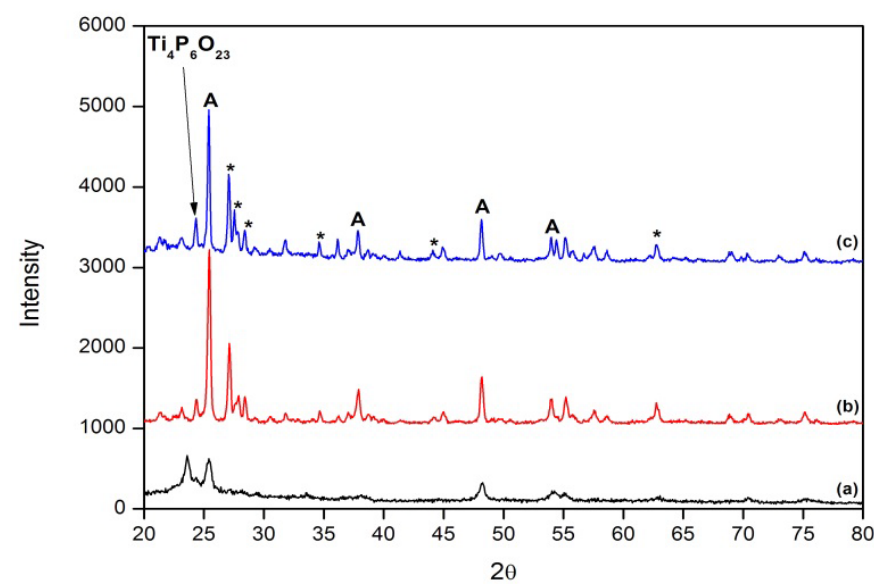

Fig. 1. Comparison XRD analysis of sample NFP-0.5, method A, prepared at varying temperatures. (a) $500{ }^{\circ} \mathrm{C}$, (b) $900{ }^{\circ} \mathrm{C}$, and (c) $1100{ }^{\circ} \mathrm{C}$.

* indicates the presence of $(\mathrm{TiO})_{2} \mathrm{P}_{2} \mathrm{O}_{7}, \mathrm{~A}=$ Anatase

A clear contrast can be seen between method A and method B when comparing Fig. 1 and Fig. 2. The (TiO) ${ }_{2} \mathrm{P}_{2} \mathrm{O}_{7}$ seen in method $\mathrm{A}$ is absent in all samples except for the material calcined at $900{ }^{\circ} \mathrm{C}$. The anatase phase can be seen to be developing from $500{ }^{\circ} \mathrm{C}$ and is seen to have fully evolved by $700{ }^{\circ} \mathrm{C}$. Two defined peaks are seen alongside the anatase phase in samples prepared at $700{ }^{\circ} \mathrm{C}$ and $800{ }^{\circ} \mathrm{C}$ which have been identified as belonging to titanium pyrophosphate, $\mathrm{TiP}_{2} \mathrm{O}_{7}$. These peaks are located at 22.6 and $27.7^{\circ}$ (Supporting information Fig. S.2). When the material was further calcined at $900{ }^{\circ} \mathrm{C}$, the rutile phase of titanium dioxide is formed in conjunction with the conversion of $\mathrm{TiP}_{2} \mathrm{O}_{7}$ to $(\mathrm{TiO})_{2} \mathrm{P}_{2} \mathrm{O}_{7}$, the phase identified in samples prepared using method $\mathrm{A}$. The conversion between $\mathrm{TiP}_{2} \mathrm{O}_{7}$ and $(\mathrm{TiO})_{2} \mathrm{P}_{2} \mathrm{O}_{7}$ has been confirmed using Raman spectroscopy. 


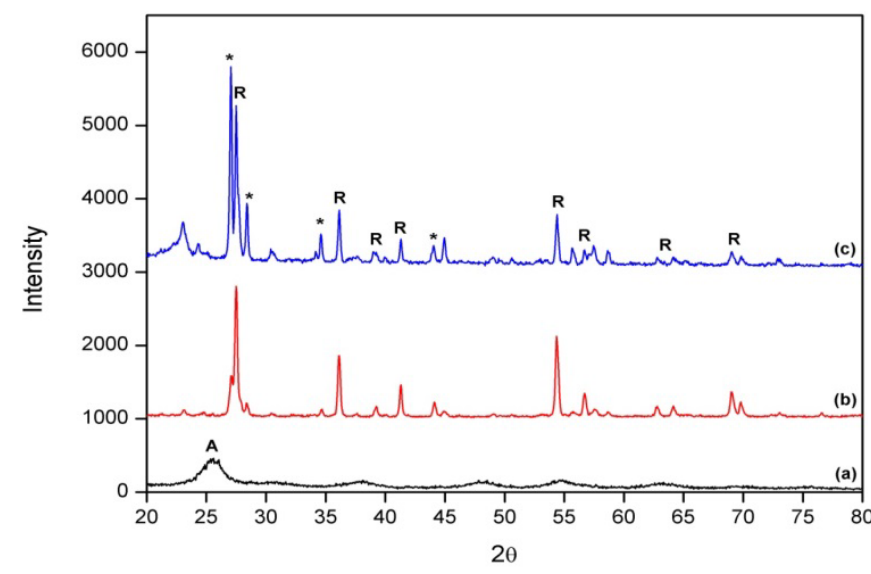

Fig. 2. Comparison XRD analysis of sample NFP-0.5, Method B, prepared at varying temperatures from $500-$ $1100{ }^{\circ} \mathrm{C}$. (a) $500{ }^{\circ} \mathrm{C}$, (b) $900{ }^{\circ} \mathrm{C}$ and (c) $1100{ }^{\circ} \mathrm{C}$.

* denotes $(\mathrm{TiO})_{2} \mathrm{P}_{2} \mathrm{O}_{7}, \mathrm{R}=$ Rutile

A comparison is made between different doping systems highlighting the effects of the individual dopants against co-doping systems on the titania crystal structure (Supporting information Fig. S.3). These systems are taken from single-source co-doping such as ammonium hexafluorophosphate (NFP) and doping containing individual dopants such as $\mathrm{N}, \mathrm{F}$ and $\mathrm{P}$. The $\mathrm{N}$-doped $\mathrm{TiO}_{2}$ shows the full formation of the rutile phase with only nitrogen present. The F-doped $\mathrm{TiO}_{2}$ shows a mixture of anatase and rutile present in the sample. $\mathrm{P}$ doped $\mathrm{TiO}_{2}$ shows the development of (TiO) ${ }_{2} \mathrm{P}_{2} \mathrm{O}_{7}$ at 22.6 and $27.8^{\circ}$ alongside the anatase phase. These peaks can be seen in samples NFP: $\mathrm{TiO}_{2}$ (ratio of 2:1) and NFP: $\mathrm{TiO}_{2}$ (ratio of $0.5: 1$ ) along with other peaks seen at 24.4 and $27.2^{\circ}$. It can be concluded from comparing the peaks seen in the phosphorus only doping that the additional peaks seen when all three dopants are present are not due to the nitrogen or fluorine present in the codoped samples, but to the phosphorus present. This conclusion is supported by XPS analysis performed on samples incorporated with ammonium hexafluorophosphate (NFP) to determine the $\mathrm{N}, \mathrm{F}$ or $\mathrm{P}$ incorporation. In method $\mathrm{A}$, a trend is seen in samples calcined between $600-1000{ }^{\circ} \mathrm{C}$. At $600{ }^{\circ} \mathrm{C}$, a particle size of $22.3 \mathrm{~nm}$ was calculated using the Scherrer equation. As the temperature is increased a small increase is seen up to $29.5 \mathrm{~nm}$ at $1000{ }^{\circ} \mathrm{C}$, with a large increase up to $40.7 \mathrm{~nm}$ seen at $1100{ }^{\circ} \mathrm{C}$. Method B shows low initial values of $3.9 \mathrm{~nm}$ consistent with pure $\mathrm{TiO}_{2}$ at low temperatures such as $500{ }^{\circ} \mathrm{C}$. A large increase is then seen when the calcination temperature was increased to $700{ }^{\circ} \mathrm{C}(27.8 \mathrm{~nm})$. As the temperature of calcination used was increased, the crystalline sizes calculated were seen to also increase, with $30.8 \mathrm{~nm}$ being measured at $900{ }^{\circ} \mathrm{C}$, where the rutile phase is initially detected alongside $(\mathrm{TiO})_{2} \mathrm{P}_{2} \mathrm{O}_{7}$. Particle sizes increase with heat treatment up to $41.0 \mathrm{~nm}$ at $1100{ }^{\circ} \mathrm{C}$ (Supporting information Table S.1). XRD was also utilised to calculate the anatase or rutile presence in each sample by use of the Spurr equation. Table 1 highlights the anatase to rutile percentage in each sample, showing $100 \%$ anatase in all samples prepared using method A except for the sample calcined at $1100{ }^{\circ} \mathrm{C}$, which showed anatase to be present at $61.6 \%$ compared to rutile at $31.4 \%$. Method B differed greatly in that there were no mixed phase samples, with $100 \%$ anatase present in all up to and including $800{ }^{\circ} \mathrm{C}$, and $100 \%$ rutile seen from $900{ }^{\circ} \mathrm{C}$ up to $1100{ }^{\circ} \mathrm{C}$.

Table 1. Anatase to rutile percentage (\%) calculated using the Spurr equation

\begin{tabular}{|l|l|r|r|r|r|}
\hline $\begin{array}{l}\text { Sample } \\
\text { Name }\end{array}$ & $\begin{array}{l}\text { Temp. of } \\
\text { calcination } \\
\left({ }^{\circ} \mathbf{C}\right)\end{array}$ & \multicolumn{4}{|c|}{$\begin{array}{l}\text { Anatase/ Rutile } \\
\text { Percentage Ratio (\%) }\end{array}$} \\
\hline & & \multicolumn{1}{|c|}{ Method A } & \multicolumn{1}{c|}{ Method B } \\
\hline & & \multicolumn{1}{c|}{ A } & \multicolumn{1}{c|}{ R } & \multicolumn{1}{c|}{ A } & \multicolumn{1}{c|}{ R } \\
\hline NFP-0.5 & 400 & 100 & 0 & 0 & 0 \\
\hline NFP-0.5 & 500 & 100 & 0 & 100 & 0 \\
\hline NFP-0.5 & 600 & 100 & 0 & 100 & 0 \\
\hline NFP-0.5 & 700 & 100 & 0 & 100 & 0 \\
\hline NFP-0.5 & 800 & 100 & 0 & 100 & 0 \\
\hline NFP-0.5 & 900 & 100 & 0 & 0 & 100 \\
\hline NFP-0.5 & 1000 & 100 & 0 & 0 & 100 \\
\hline NFP-0.5 & 1100 & 68.6 & 31.4 & 0 & 100 \\
\hline
\end{tabular}

\subsection{XPS}

Analysis of method A doped samples indicates the presence of phosphorus, nitrogen and fluorine at samples calcined at $500{ }^{\circ} \mathrm{C}$ (Supporting information Fig. S.4) however only phosphorus is evident when temperatures are increased to $900{ }^{\circ} \mathrm{C}$. The photoelectron peak for fluorine seen at approximately $685.1 \mathrm{eV}\left(500{ }^{\circ} \mathrm{C}\right)$ is attributed to the F1s species which is typical for the linkage of fluorine onto the structure in the form of Ti$\mathrm{O}-\mathrm{F}[35,40,45]$. The concentration for this is determined to be 6.71 at\%. Fluorine can be located at two other locations, $684.3 \mathrm{eV}$ indicating adsorption to the outer surface of the doped titania or $688.4 \mathrm{eV}$ signifying doping into the titania lattice in the form of a solid solution $\mathrm{TiO}_{2-\mathrm{x}} \mathrm{F}_{\mathrm{x}}$ [41]. When the calcination temperature is increased to $900{ }^{\circ} \mathrm{C}$, all characteristic fluorine peaks are absent. This is due to the fluorine that is present at low temperatures being removed through the calcination process to high temperatures and is not available for any interactions with the $\mathrm{TiO}_{2}$. At $500{ }^{\circ} \mathrm{C}$, nitrogen is detected to be present at a concentration of 1.07 at $\%$ and 
located at $401.2 \mathrm{eV}$. Binding energies of approximately $401 \mathrm{eV}$ are usually indicative of NO suggesting interstitial nitrogen. It is suggested that a location of $401.2 \mathrm{eV}$ is due to the $\mathrm{N} 1 s$ binding energy in the environment of $\mathrm{O}-\mathrm{Ti}-\mathrm{N}$ at this temperature $[31,46]$. However, the characteristic nitrogen peak located at 396 $\mathrm{eV}$ for the $\mathrm{N}-\mathrm{Ti}-\mathrm{N}$ environment is not present suggesting that lattice bonding is not occurring at this time. As the temperature increases, the presence of the N1s peak is not detected, which is also due to its removal throughout the calcination process. In comparison to the fluorine and the nitrogen analysis, the phosphorus is present at calcination temperatures as high as $1000{ }^{\circ} \mathrm{C}$. The location of the P2p is measured at $134.1 \mathrm{eV}$ at $500{ }^{\circ} \mathrm{C}$ (Fig. 3). A slight increase in binding energy is observed as the annealing temperature is increased, $134.7 \mathrm{eV}$ (900 $\left.{ }^{\circ} \mathrm{C}\right)$ and $134.6 \mathrm{eV}\left(1000{ }^{\circ} \mathrm{C}\right)$. These values suggest that the $\mathrm{P} 2 p$ detected is due to the $\mathrm{P}$ in a pentavalent oxidation state denoted by $\mathrm{P}^{5+}$ [47]. There is a significant absence of the characteristic binding energy peak for Ti$\mathrm{P}$ which is generally located at $128.6 \mathrm{eV}$ [48] (Fig. 3). It was expected that phosphorus, with an ionic radius of $0.35 \AA$, could effectively replace the Ti atom (0.67 $\AA$ ). Analysing the Ti2 $p$ peak can give an indication to whether surface oxygen vacancies are formed. A peak present at approximately $457.4 \mathrm{eV}$ is indicative of $\mathrm{Ti}^{3+}$, which is formed upon the reduction of Ti. The absence of this peak can be presumed to show that Ti has not been reduced and therefore shows the absence of surface oxygen vacancies [49]. These results therefore show that $\mathrm{Ti}^{4+}$ is not replaced by $\mathrm{P}^{5+}$. It can therefore be concluded that the phosphorus is bounded to the surface of $\mathrm{TiO}_{2}$ particles. When samples prepared using method B were analysed, similar results were seen in regards to the presence of Ti2p. This shows that neither method induced the formation of surface oxygen vacancies. The analysis of phosphorus is also similar to method A. Phosphorus is present in all samples, even at high as $1000{ }^{\circ} \mathrm{C}$ (12.64 at\%). The location of the $\mathrm{P} 2 p$ peaks were at $134.01 \mathrm{eV}$ and $134.04 \mathrm{eV}$ at $500^{\circ} \mathrm{C}$ and $900{ }^{\circ} \mathrm{C}$ respectively, with a slight shift seen to $133.82 \mathrm{eV}$ for samples calcined at $1000{ }^{\circ} \mathrm{C}$. As mentioned above, this was determined to be due to the presence of the $\mathrm{P}$ in a pentavalent-oxidation state denoted by $\mathrm{P}^{5+}$. In contrast to method A doping, nitrogen is detected in both $500{ }^{\circ} \mathrm{C}$ and $900{ }^{\circ} \mathrm{C}$ with trace amounts present at $1000{ }^{\circ} \mathrm{C}(0.41$ at\%). At $1000{ }^{\circ} \mathrm{C}$, there is a shift from $400.24 \mathrm{eV}$ at 900 ${ }^{\circ} \mathrm{C}$ down to $397.80 \mathrm{eV}$. This shift is indicative of the $\mathrm{N}$ Ti-N environment suggestive of lattice bonding (396 $\mathrm{eV}$ ). The presence of the $\mathrm{N}-\mathrm{Ti}-\mathrm{N}$ bonding is confirmed using FT-IR analysis seen below in Fig. 7, where the OTi-O peak has been shifted upfield from $454 \mathrm{~cm}^{-1}$ (method A) to $513 \mathrm{~cm}^{-1}$ (method B). This is due to the doping of the material, in this case with nitrogen leading us to believe that this shift is due to the occurrence of the $\mathrm{N}-\mathrm{Ti}-\mathrm{N}$ bond confirmed here by XPS. Another difference is the notable absence of fluorine from all samples prepared using method $\mathrm{B}$ in comparison to method A which contained 6.71 at $\%$ at $500{ }^{\circ} \mathrm{C}$. (Table 2).

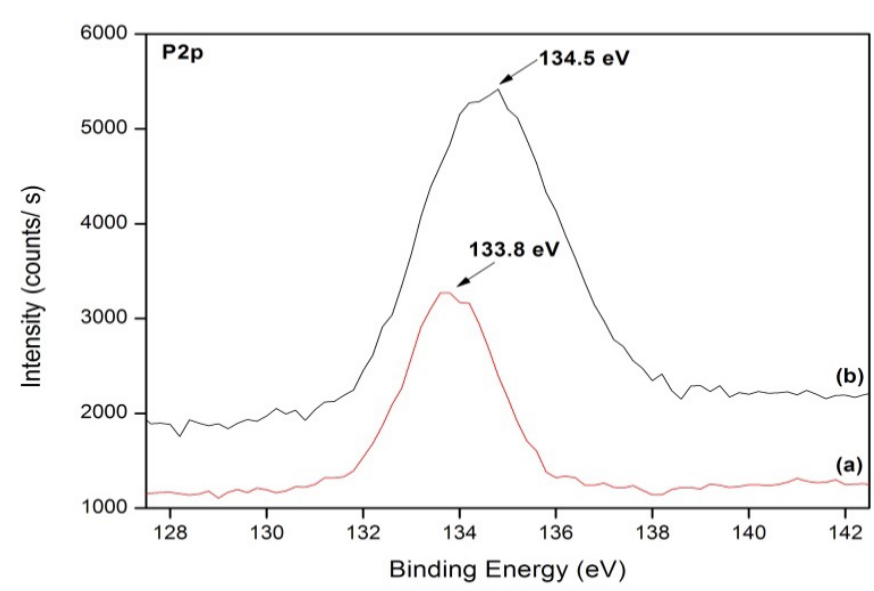

Fig. 3. Comparison P 2p XPS spectra for samples NFP0.5 calcined at $1000{ }^{\circ} \mathrm{C}$ (a) method B and (b) method A

Table 2. XPS analysis of method A, method B and undoped $\mathrm{TiO}_{2}$ samples calcined at 500, 900 and 1000 ${ }^{\circ} \mathrm{C}$, outlining the atomic concentration of each element present

\begin{tabular}{|l|l|l|l|l|l|}
\hline \multirow{2}{*}{$\begin{array}{l}\text { Procedure and } \\
\text { Sample Name }\end{array}$} & \multicolumn{5}{|l|}{ Atomic \% } \\
\cline { 2 - 6 } & $\begin{array}{l}\text { Temp } \\
\left({ }^{\circ} \mathbf{C}\right)\end{array}$ & Ti 2p & P 2p & F 1s & N1s \\
\hline Method A & & & & & \\
\hline NFP -0.5 & 500 & 18.21 & 9.64 & 6.71 & 1.07 \\
\hline NFP -0.5 & 900 & 9.33 & 14.31 & - & - \\
\hline NFP - 0.5 & 1000 & 9.26 & 13.08 & - & - \\
\hline Method B & & & & & \\
\hline NFP - 0.5 & 500 & 9.86 & 14.62 & - & 0.63 \\
\hline NFP-0.5 & 900 & 10.54 & 11.64 & - & 0.68 \\
\hline NFP-0.5 & 1000 & 11.90 & 12.64 & - & 0.41 \\
\hline Un-doped & & & & & \\
\hline $\mathrm{TiO}_{2}$ & 500 & 24.95 & - & - & - \\
\hline $\mathrm{TiO}_{2}$ & 900 & 22.71 & - & - & - \\
\hline $\mathrm{TiO}_{2}$ & 1000 & 26.35 & - & - & - \\
\hline
\end{tabular}

\subsection{Raman Spectroscopy}

Raman spectroscopy was used to analyse the samples and to identify their phase whether it be anatase, rutile or amorphous. When studying the effect of method A doping, samples ranging from $400-1000{ }^{\circ} \mathrm{C}$ were analysed. At a temperature of $400{ }^{\circ} \mathrm{C}$, only amorphous material can be detected, whereas at a temperature of $500{ }^{\circ} \mathrm{C}$, the amorphous material has successfully 
converted to pure anatase. This anatase phase is seen to be retained at temperatures $500{ }^{\circ} \mathrm{C}$ to $1000{ }^{\circ} \mathrm{C}$. Method $\mathrm{B}$ in comparison retains $100 \%$ anatase up to and including $800{ }^{\circ} \mathrm{C}$. After this temperature, method $\mathrm{B}$ showed the formation of rutile at a lower temperature $\left(900{ }^{\circ} \mathrm{C}\right.$ ) compared to $100 \%$ anatase at $1000{ }^{\circ} \mathrm{C}$ using the method A doping procedure showing that the more effective method at preparing high temperature stable anatase is by using ammonium hexafluorophosphate (method A). When looking at method A, the anatase form can be seen alongside other peaks seen from 600 ${ }^{\circ} \mathrm{C}$. These peaks appear in all N, F, P doped samples over this temperature and can be attributed to the formation of $(\mathrm{TiO})_{2} \mathrm{P}_{2} \mathrm{O}_{7}$. The majority of these peaks are labelled in Fig. 4. The location of these peaks can be seen at approx. 295, 720, 817, 856, $1025 \mathrm{~cm}^{-1}$ with other small peaks seen. These extra peaks can be attributed to P-doping of $\mathrm{TiO}_{2}$. They have been identified as being characteristic of $(\mathrm{TiO})_{2} \mathrm{P}_{2} \mathrm{O}_{7}$, with identifiable peaks seen at approximately 294, 719, 821, 858 and $1024 \mathrm{~cm}^{-1}$ [50]. The peak at $720 \mathrm{~cm}^{-1}$ is suggested to be that of a titanyl group $\left(\mathrm{TiO}^{2+}\right.$ ) and the peak at $1024 \mathrm{~cm}^{-1}$ determined to be a result of the thermal decomposition of titanium (IV) pyrophosphate $\left(\mathrm{TiP}_{2} \mathrm{O}_{7}\right)$ located at $1039 \mathrm{~cm}^{-1}$ to (TiO) ${ }_{2} \mathrm{P}_{2} \mathrm{O}_{7}$ [50]. This also indicates that $\mathrm{TiP}_{2} \mathrm{O}_{7}$ is present in the sample at lower temperatures as the peaks $1039 \mathrm{~cm}^{-1}$ has been seen to be present at $800{ }^{\circ} \mathrm{C}$.

A comparison between the two methods can be seen in Fig. 5, where the rutile peaks (method B) can be clearly distinguished from the anatase peaks (method A) alongside the titanium oxide phosphate formed.

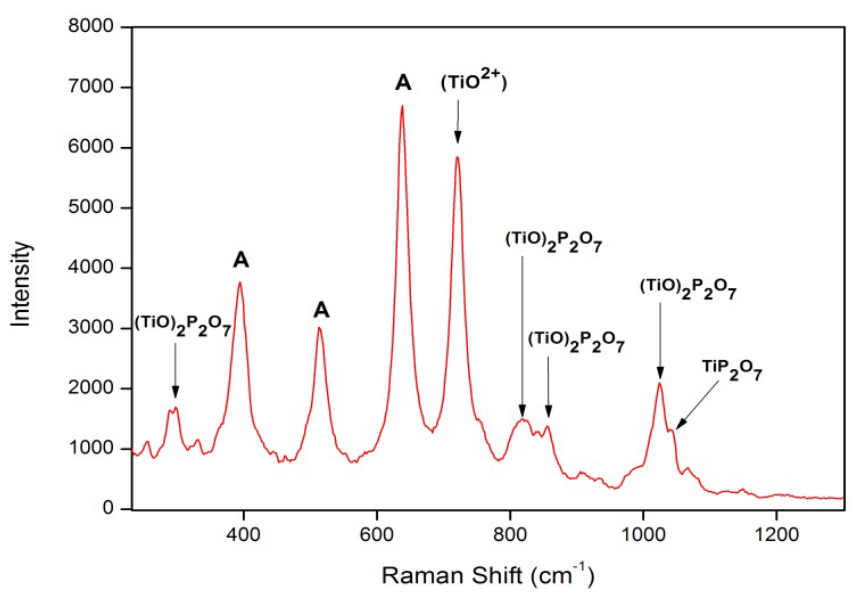

Fig. 4. Raman spectra of sample calcined at $900{ }^{\circ} \mathrm{C}$ using method A

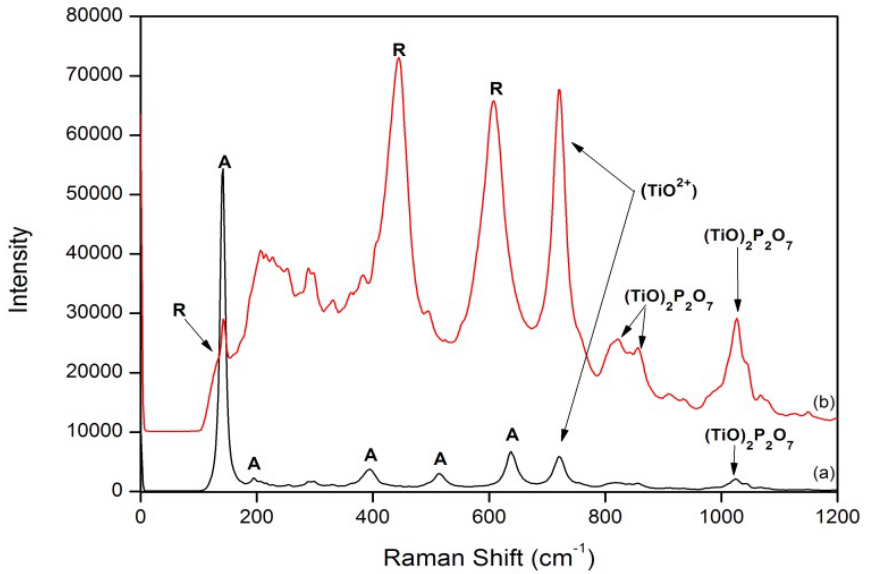

Fig. 5. Raman spectra of samples calcined at $900{ }^{\circ} \mathrm{C}$ of (a) method A and (b) method B

A comparison between 2:1 NFP: titanium dioxide (method A) with phosphoric acid in a ratio also of 2:1 dopant: titanium dioxide was made at a calcination temperature of $900{ }^{\circ} \mathrm{C}$ (Supporting information Fig. S.5). The samples selected for comparison were done so on the basis of their compositions; P-doped showing the effect of using only the P dopant and NFP-2, showing the effect of all three dopants on the titania formation. From this comparison graph it can be seen that the peaks located in the range of $1040 \mathrm{~cm}^{-1}$ are due to the presence of phosphorus in the sample. A cluster of smaller peaks between $200-400 \mathrm{~cm}^{-1}$ can be seen only in samples containing phosphorus. In samples at a higher ratio of ammonium hexafluorophosphate (above 0.5:1) the anatase peaks are not seen. This could be due to overloading of the sample with dopant that is hindering the development of the crystalline form of $\mathrm{TiO}_{2}$. A comparison of NF-2, showing the effect when $\mathrm{P}$ is absent and NFP-2 was also made showing the inability to form anatase at higher doping ratios i.e. 2:1, (Supporting information Fig. S.6). In the sample NF-2, no peaks were seen after $640 \mathrm{~cm}^{-1}$ indicating that these titanates do not form.

\subsection{Diffuse Absorbance Spectroscopy}

Band gap values calculated using diffuse absorbance measurements support the XRD and Raman results in terms of anatase and rutile formation. From the diffuse absorbance studies of samples prepared from both methods, the band gap of each sample is calculated. From Fig. 6 below, it is seen that in the case of method A doping, the wavelength was measured at $390.2 \mathrm{~nm}$, giving a calculated band gap value of $3.21 \mathrm{eV}$. A band gap value such as this is indicative of the presence of anatase. The values calculated for samples calcined between $500-1000{ }^{\circ} \mathrm{C}$, are all suggestive of the anatase 
phase. A sample calcined at $1100{ }^{\circ} \mathrm{C}$ shows a slight reduction in the band gap $(3.04 \mathrm{eV})$ as opposed to that of the $1000{ }^{\circ} \mathrm{C}$ sample $(3.18 \mathrm{eV})$. This is indicative of the formation of rutile at this temperature. The calculated band gap for the method B doping also seen in Fig. 6 for the corresponding sample was $2.92 \mathrm{eV}$ with a measured wavelength of $423.8 \mathrm{~nm}$. For samples calcined from 500 - $800{ }^{\circ} \mathrm{C}$, there is a slight decrease in the band gap values recorded, whereas samples prepared at 900 and $1000{ }^{\circ} \mathrm{C}$ show the rutile phase formation within the samples.

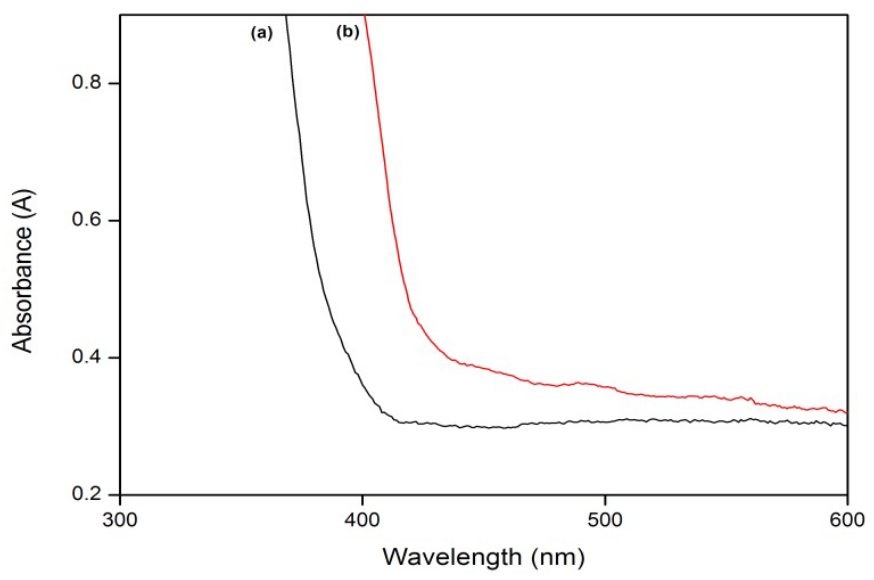

Fig. 6. Comparison spectra of the measured diffuse absorbance for (a) method A and (b) method B, both calcined at $900{ }^{\circ} \mathrm{C}$.

\subsection{Fourier Transform Infrared Spectroscopy}

The FTIR spectra of the undoped and NFP doped $\mathrm{TiO}_{2}$, method A and method B, were recorded and analysed for the purpose of determining bonds formed during doping (Fig. 7). Low frequency bands in the range of 450-560 $\mathrm{cm}^{-1}$ are indicative of Ti-O-Ti stretching vibrations. A shift in location of the Ti-O-Ti peak to a region of higher energy is believed to be due to the presence of dopants and the doping of $\mathrm{TiO}_{2}$. An explanation for the upfield shift may be the presence of nitrogen in the form of O-Ti-N or N-Ti-N [51]. The existence of O-Ti-N has also been identified by XPS. Due to the removal of dopants at higher calcination temperatures, strong peaks which appear at approximately $1619 \mathrm{~cm}^{-1}$ that indicate the deformation of $\mathrm{NH}_{2}$, have disappeared [51]. Peaks in the range of $963-1288 \mathrm{~cm}^{-1}$ are characteristic frequencies of the phosphate group $\left(\mathrm{PO}_{4}{ }^{3-}\right)$ [34]. Identifiable peaks for the asymmetric vibration of the POP bond $\left(\sim 920 \mathrm{~cm}^{-1}\right)$, the symmetrical vibration of $\mathrm{PO}_{3}\left(1035-1065 \mathrm{~cm}^{-1}\right)$ and the asymmetric vibration of $\mathrm{PO}_{3}\left(1090-1170 \mathrm{~cm}^{-1}\right)$ are seen. The peak seen between $1036-1050 \mathrm{~cm}^{-1}$ could be due to the formation of Ti-O-P bonds.

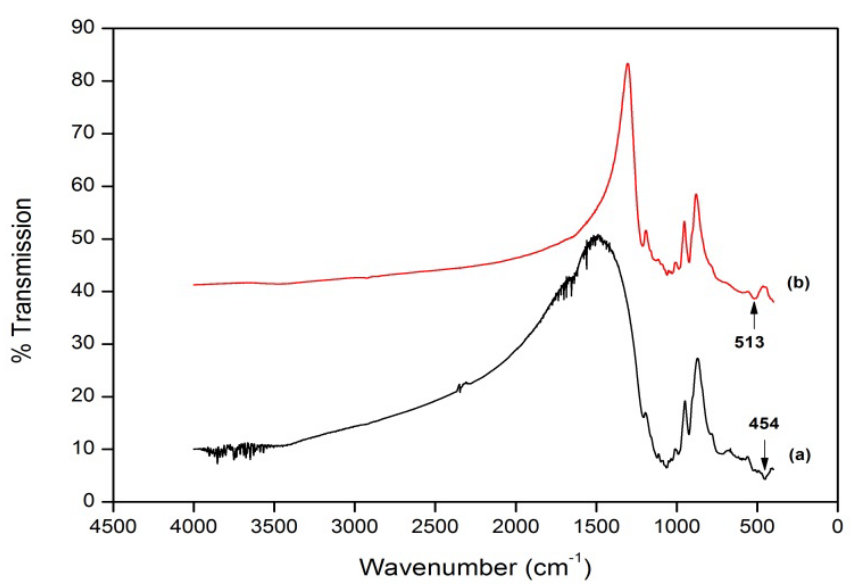

Fig. 7. Comparison spectra of the measured FT-IR for (a) method A and (b) method B, both calcined at $900{ }^{\circ} \mathrm{C}$.

\subsection{Photocatalysis}

Photocatalytic studies were carried out to measure the decomposition of rhodamine $6 \mathrm{G}$ dye to determine the rates of reaction for each sample using pseudo-firstorder rate kinetics with a plot of $\ln (\mathrm{A}) \mathrm{vs}$. time $\mathrm{t}$ giving a straight line with a slope of $-k$. These were also compared to the measured results for undoped $\mathrm{TiO}_{2}$ samples. The calculated $k$ for the undoped $\mathrm{TiO}_{2}$ sample was $0.138 \mathrm{~min}^{-1}$, over 6 times faster than that calculated for NFP-0.5 (method A) and over 2 times faster than NFP-0.5 (method B), all measured at $500{ }^{\circ} \mathrm{C}$. This is due to the complete formation of anatase in the undoped sample compared to that of the amorphous/ anatase development seen in the doped samples. When temperatures are increased to $900{ }^{\circ} \mathrm{C}$, a dramatic decrease was seen in the rate constant $k$ calculated for the undoped $\mathrm{TiO}_{2}\left(0.039 \mathrm{~min}^{-1}\right)$ and the method $\mathrm{B}$ prepared sample $\left(0.007 \mathrm{~min}^{-1}\right)$, with an increase in $k$ seen for method A $\left(0.070 \mathrm{~min}^{-1}\right)$. This is due to the presence of the stable anatase phase in the method A sample at $900{ }^{\circ} \mathrm{C}$, whereas the method $\mathrm{B}$ and undoped samples were $100 \%$ rutile at the same temperature. It is seen that the phase composition of the samples plays a part in the resulting rates calculated. From $500-900{ }^{\circ} \mathrm{C}$, and as a more crystalline anatase is formed, the $k$ value measured increases from $0.019 \mathrm{~min}^{-1}$ to $0.070 \mathrm{~min}^{-1}$. As the temperature is further increased, the formation of rutile is seen in the sample calcined at $1100{ }^{\circ} \mathrm{C}$, showing an anatase to rutile percentage of $68.6 \%$ anatase and 31.4 $\%$ rutile (Table 1 ). This explains the reduction in the photocatalytic activity of the sample $\left(0.042 \mathrm{~min}^{-1}\right)$. In comparison, as the anatase phase converts to the rutile phase, the rates drop from $0.054 \mathrm{~min}^{-1}$ to $0.005 \mathrm{~min}^{-1}$ for samples prepared using method B. For each method, the most effective sample was seen to be that which was calcined at $900{ }^{\circ} \mathrm{C}$ (method A) and $600{ }^{\circ} \mathrm{C}$ (method B). 
The known standards, Degussa P25 and VLP7000, were used as comparisons. In the case of Degussa P25, the initial rates $\left(0.202 \mathrm{~min}^{-1}\right)$ were much improved on the prepared samples. To compare like with like, samples of Degussa were then calcined at temperatures of 500, 900, 1000 and $1100{ }^{\circ} \mathrm{C}$. It was then seen that as the calcination temperature was increased, the rate of activity of Degussa decreased radically leading to rates of $0.031 \mathrm{~min}^{-1}$ at $1100{ }^{\circ} \mathrm{C}$, showing a reduction in the $k$ value of 6 times. The reduction in the $k$ calculated for the calcined Degussa samples can be explained by the increase in crystalline size upon heat treatment. Typically Degussa P25 has an average crystalline size of $21 \mathrm{~nm}$ with a specific surface area of $50 \mathrm{~m}^{2} / \mathrm{g}$ [52]. From the XRD spectra obtained for the sample calcined at 500 ${ }^{\circ} \mathrm{C}$, an average crystalline size of $39.3 \mathrm{~nm}$ was measured, an increase of nearly twice the original size. It can also be assumed that an increase in particle size results in a decrease in surface area. These two factors contribute to the reduction in the reaction rates observed at $500{ }^{\circ} \mathrm{C}$. These results also apply to samples calcined at 900 and $1100{ }^{\circ} \mathrm{C}$, both of which are $100 \%$ rutile with particle sizes averaging over $40 \mathrm{~nm}$. Similar can be said for Kronos VLP7000, a commercial visible light active titania, where the powder, without calcination, recorded a degradation rate of $0.027 \mathrm{~min}^{-1}$ but when temperatures were increased to $1100{ }^{\circ} \mathrm{C}$, the rate constant $k$ decreased to $0.002 \mathrm{~min}^{-1}$, showing to be ten times slower at this high temperature (Supporting information Table S.2).

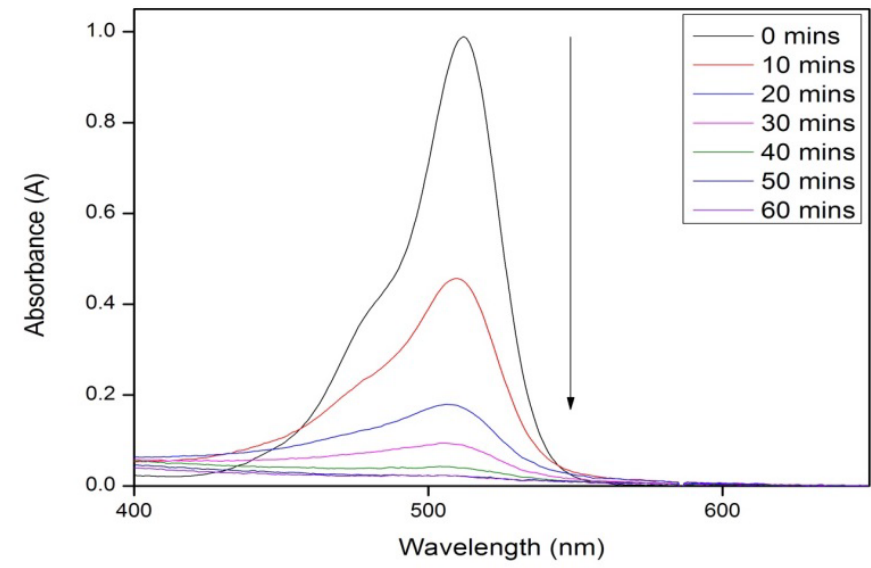

(b)

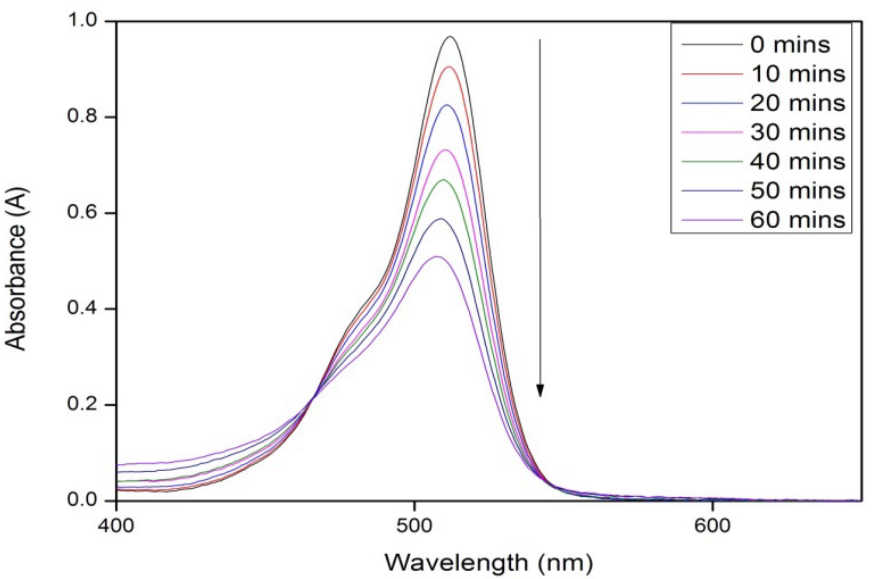

(c)

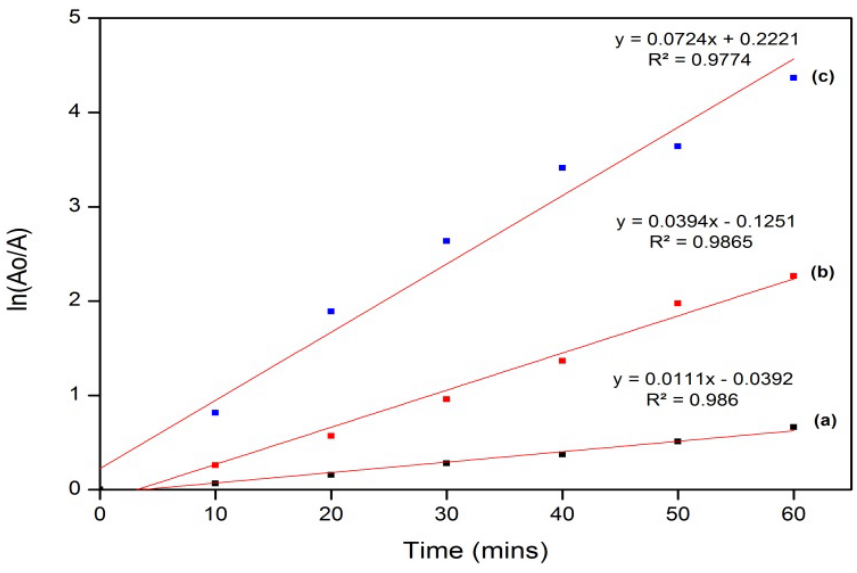

Fig. 8. Kinetic study of undoped sample compared to samples prepared by both methods calcined at $900{ }^{\circ} \mathrm{C}$. Ao is the initial absorbance and $A$ is the absorbance after a time of the rhodamine dye degradation. Absorption spectra of rhodamine dye degradation by sample (a) method B, NFP-0.5 (900 $\left.{ }^{\circ} \mathrm{C}\right)$ (b) undoped $\mathrm{TiO}_{2}\left(900{ }^{\circ} \mathrm{C}\right)$ and (c) method A, NFP-0.5 (900 $\left.{ }^{\circ} \mathrm{C}\right)$. 


\section{Discussion}

A clear difference between the phase developments using these two methods has been thoroughly investigated within this paper. Nitrogen, fluorine and phosphorus are ions which have all been analysed in detail in previous works, but to date, no work has been published with the three dopants in one system. This leads to difficulties in attributing doping mechanisms to the ammonium hexafluorophosphate system (method A). From the XRD results, there is a clear difference in the materials produced from the two doping methods used. Both methods result in the development of the material (TiO) ${ }_{2} \mathrm{P}_{2} \mathrm{O}_{7}$, method A from the temperature of $400{ }^{\circ} \mathrm{C}$ and method $\mathrm{B}$ from $700{ }^{\circ} \mathrm{C}$, yet the different methods had different effects on the stability of the titanium phase. Method A is seen to be the most effective method to form and retain the anatase phase at high temperatures when tested against method $B$. This could be due to the actual effective doping of the titania. As we know, the three dopants within the ammonium hexafluorophosphate system all have different yet positive effects on the titania and its reactivity as a photocatalyst.

According to the XPS results, at high temperatures the only dopant detected is that of phosphorus in its $\mathrm{P}^{5+}$ form. Phosphorus is well known to stabilise the $\mathrm{TiO}_{2}$ framework, leading us to believe that the phosphorus present, though not in the form of Ti-O-P, is being utilised by the titania system to retain stable anatase at high temperatures. Surface phosphorus species may also contribute to the enhanced properties of doped $\mathrm{TiO}_{2}$ by acting as trapping sites to capture the $\mathrm{e}^{-}$in the conduction band leading to an enhanced photo-activity due to the extended electron/ hole separation [33].

Fluorine linkage to titania in the form of Ti-O-F, which is seen in method A, could be the reason the stable anatase phase is retained at high temperatures. As discussed in detail by Padmanabhan et al. [41] an introduction of fluorine has the ability to inhibit the rutile phase nucleation. It states that under fluorination conditions, the reaction rate of crystal growth as well as crystallisation is slowed down due to fact that the fluorinated clusters may be repelling each other [41]. It is only after the elimination of fluorine, through calcination at higher temperatures, that the rutile phase nucleation can occur [41]. In comparison to method A, when analysed, method B showed no presence of fluorine in all samples. This could be due to the doping method which could be inhibiting the fluorine from entering the $\mathrm{TiO}_{2}$ lattice due to the initial urea doping the $\mathrm{TiO}_{2}$ lattice first. The fluorine could be present before calcination but was easily burnt off as temperatures increased, $500{ }^{\circ} \mathrm{C}-1100{ }^{\circ} \mathrm{C}$, leading to no detection of fluorine by XPS. The presence of fluorine could play a pivotal role in the delayed rutile formation using method A in relation to method B. Fig. 9 seen below, may give some insight into the impurity states for each element to be considered. The F2 $p$ states lie below the bottom of the $\mathrm{O} 2 p$ valence band $(1.19 \mathrm{eV})$ [30], and is seen in the form of substitutional fluorine in regards to oxygen. The extra electron associated with the heteroatom is localized by $\mathrm{Ti}^{4+}$ ions. This results in the formation of shallow electron states $\left(\mathrm{Ti}^{3+}\right)$ located 0.8 $\mathrm{eV}$ below the conduction band [53]. Doping of $\mathrm{TiO}_{2}$ with fluorine has been found to not have any significant effect in the absorbance edge of titania.

Nitrogen was present in both methods in the form of the interstitial bonding NO which results in the formation of discrete energy levels located $0.73 \mathrm{eV}$ above the valence band which can be referred to as midgap states $[1,54]$ (Fig. 9). Nitrogen was also present in the form of substitutional N-Ti-N in method B, with midgap levels located at $0.14 \mathrm{eV}$ above the valence band [55]. This could be due to the enhanced doping of nitrogen into the titania lattice during stage 1 of doping. This interaction was also confirmed by FT-IR with an upfield shift of the confirmation Ti-O peak up to $513 \mathrm{~cm}^{-1}$ as seen above. It should be stated that previous results have shown from local density approximation (LDA) calculations that the band gaps of these anion doped materials are not actually narrowing. It is the isolated impurity states that are located between the valence and the conduction bands that produce the observed visible-light absorption results [55].

'Isolated Impurity States' in the Band Gap

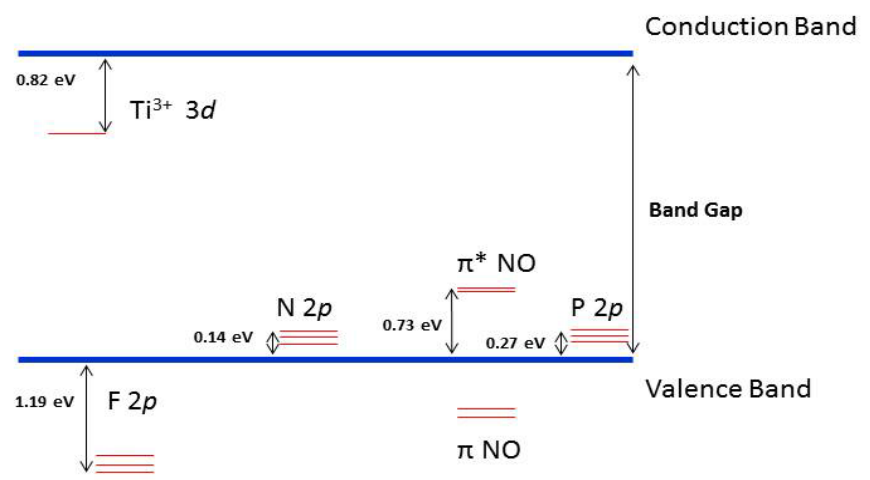

Fig. 9. Schematic illustration of localized impurity energy states for the substitutionally doped $\mathrm{TiO}_{2}$ (adapted from ref 1).

There are many factors that affect the photocatalytic properties of $\mathrm{TiO}_{2}$. These include phase composition, crystallinity, particle size, surface area, retention of 
added dopant in the prepared material, adsorption properties of the dye onto the surface of the $\mathrm{TiO}_{2}$ used, rate of electron-hole recombination and the number of electrons created [54]. In the current investigation, the photocatalytic activity of the samples was greatly affected by the differing titanate formations seen between the two methods and the presence of the dopant fluorine at lower temperatures. As mentioned above, fluorine is known to successfully inhibit the anatase to rutile transition. In this study, fluorine is only present in method $\mathrm{A}\left(500{ }^{\circ} \mathrm{C}\right)$ at an At \% of 6.71. The presence of this substituted fluorine in method A plays a pivotal role in the retention of the stable anatase phase at higher calcination temperatures when compared with method B where fluorine was absent from all samples. Method A also showed the early formation of the phosphate (TiO) ${ }_{2} \mathrm{P}_{2} \mathrm{O}_{7}\left(400{ }^{\circ} \mathrm{C}\right)$. The resulting anatase that forms has a much higher stability at higher temperatures when compared to method $\mathrm{B}$ which showed the formation of $\mathrm{TiP}_{2} \mathrm{O}_{7}$ before the eventual growth of $(\mathrm{TiO})_{2} \mathrm{P}_{2} \mathrm{O}_{7}(700$ $\left.{ }^{\circ} \mathrm{C}\right)$. It is believed that the introduction of phosphorus, in the form of $(\mathrm{TiO})_{2} \mathrm{P}_{2} \mathrm{O}_{7}$, successfully stabilised the anatase phase at lower temperatures leading to a more stable anatase at higher temperatures and a delayed transition to rutile. This result is consistent with the observation by Periyat et al, where the formation of the intermediate phase $\mathrm{TiOSO}_{4}$ delayed rutile formation. ${ }^{32}$ Method A displays $100 \%$ anatase up to $1000{ }^{\circ} \mathrm{C}(0.057$ min-1) and a relatively high quantity of anatase at 1100 ${ }^{\circ} \mathrm{C}$, exhibiting $68.6 \%$ (0.042 min-1). In method B, pure anatase was seen at low temperatures $\left(500-600{ }^{\circ} \mathrm{C}\right)$ leading to high reaction rates calculated for these samples (Table A.1). As the temperature was increased, the $\mathrm{TiP}_{2} \mathrm{O}_{7}$ was formed and the rates calculated were seen to decrease dramatically, leading us to believe that this form of titanate is photocatalytically inactive. After $700{ }^{\circ} \mathrm{C}$, all samples were deemed inactive as the rates measured were very low. Even though the introduction of $\mathrm{P}$ into the $\mathrm{TiO}_{2}$ solid system results in the formation of $(\mathrm{TiO})_{2} \mathrm{P}_{2} \mathrm{O}_{7}$ and $\mathrm{TiP}_{2} \mathrm{O}_{7}$, it is worth noting that in the presence of ( $\mathrm{TiO})_{2} \mathrm{P}_{2} \mathrm{O}_{7}$ (method $\mathrm{A}$ ), clear photoactivity can be seen yet is significantly reduced when $\mathrm{TiP}_{2} \mathrm{O}_{7}$ is present (method $\mathrm{B}$ ). After $800{ }^{\circ} \mathrm{C}$, the $(\mathrm{TiO})_{2} \mathrm{P}_{2} \mathrm{O}_{7}$ phase is detected alongside the inactive rutile phase. The retention of the photoactive phase anatase at such high temperatures is believed to contribute to improving method A.

The formation of these differing phosphates also plays a part in the particle size of the resulting samples. Typically in literature, the 'critical size' on the phase boundary between nanocrystalline anatase and rutile transition occurs around $<14 \mathrm{~nm}$, assuming the surface stress equals the surface free energy in value [56].
Thermodynamically, it can be concluded that when the particle size is below $14 \mathrm{~nm}$, anatase is more stable than rutile [57]. Rutile particles begin to form with the introduction of energy to the materials in the form of heat (calcination) and once formed the rutile crystals grow considerably faster [57]. From our results, it can be seen that we have retained anatase at much higher sizes than $14 \mathrm{~nm}$. In method $\mathrm{A}$, the trend seen in samples calcined between $600-1000{ }^{\circ} \mathrm{C}$ can be mirrored in the photocatalysis results (Table A.1) where an increase in reaction rates is seen with increasing calcination temperatures up to $900{ }^{\circ} \mathrm{C}$ with particle sizes increasing from $22.3 \mathrm{~nm}$ at $600{ }^{\circ} \mathrm{C}$ to $27.5 \mathrm{~nm}$ at $900{ }^{\circ} \mathrm{C}$. After this temperature, decreasing rates are observed. This could be due to the anatase being at an optimum at $900{ }^{\circ} \mathrm{C}$, with the anatase to rutile transition beginning to occur at $1000{ }^{\circ} \mathrm{C}$ even though visible rutile is seen only from $1100{ }^{\circ} \mathrm{C}(40.7 \mathrm{~nm})$. Method B has low initial values of $3.9 \mathrm{~nm}$ consistent with pure $\mathrm{TiO}_{2}$ [58], at low temperatures, in this case $500-600{ }^{\circ} \mathrm{C}$. A large increase is then seen when the calcination temperature was increased to $700^{\circ} \mathrm{C}(27.8 \mathrm{~nm})$, which is due to the increased crystallinity and the simultaneous formation of the phosphate, $\mathrm{TiP}_{2} \mathrm{O}_{7}$, at this stage. As further calcination is employed, crystalline size is seen to increase, with $30.8 \mathrm{~nm}$ being measured at $900{ }^{\circ} \mathrm{C}$, where the rutile phase is initially detected alongside $(\mathrm{TiO})_{2} \mathrm{P}_{2} \mathrm{O}_{7}$. Particle sizes increase with heat treatment up to $41.0 \mathrm{~nm}$ at $1100{ }^{\circ} \mathrm{C}$. The crystalline size for each sample can also go towards explaining the photocatalysis results as an increased particle size suggests fewer reactivity sites on the surface for the interaction between sample and the organic dye used.

When $\mathrm{TiO}_{2}$ is irradiated with a light source of appropriate wavelength, photoexcitation of an electron $\left(\mathrm{e}^{-}\right)$from valence band to the conduction band occurs and consequently a hole $\left(h^{+}\right)$is created. The hole further react with water and oxygen to form radicals such as ${ }^{\circ} \mathrm{OH}$ and ${ }^{\circ} \mathrm{O}_{2}{ }^{-}$

$\mathrm{h} v \rightarrow \mathrm{h}^{+}{ }_{\mathrm{BB}}+\mathrm{e}_{\mathrm{CB}}^{-}$

$\mathrm{h}^{+} \mathrm{VB}+$ water $\rightarrow{ }^{\circ} \mathrm{OH}+\mathrm{H}^{+}$

$\mathrm{e}^{-}{ }_{\mathrm{CB}}+\mathrm{O}_{2} \rightarrow{ }^{\circ} \mathrm{O}_{2}^{-}$

The photocatalytic decomposition of the rhodamine dye occurs via a direct photoreaction by the ${ }^{\circ} \mathrm{OH}$ radicals. 


\section{Conclusions}

In this study, the preparation of high temperature stable anatase produced by two differing methods was investigated. From the XRD analysis, method A (single dopant) was seen to provide a stable anatase form at high temperatures such as $1000{ }^{\circ} \mathrm{C}$ compared to method B (multiple dopants) which exhibited $100 \%$ rutile from a calcination temperature of $900{ }^{\circ} \mathrm{C}$. This property can be possibly explained by the presence of titanium oxide phosphates in method $\mathrm{A}$ at these high temperatures which seem to be significantly diminished in the samples prepared using method B. From the XPS data, it was seen that the nitrogen and fluorine which was present at $500{ }^{\circ} \mathrm{C}$ had been removed due to calcination at temperatures of $900{ }^{\circ} \mathrm{C}$ and $1000{ }^{\circ} \mathrm{C}$. Photocatalysis studies showed that as the calcination temperature was increased, the reactivity of the method A prepared samples increased due to the presence of stable anatase, whereas the reaction rates for method $B$ were seen to decrease with increasing temperatures. It was concluded that method A has been seen to be the most effective method at preparing a stable photoactive catalyst at high temperatures, with the sample prepared at $900{ }^{\circ} \mathrm{C}$ showing the highest rate of reaction overall. The retention of the phosphorus has proved to be effective in stabilising the $\mathrm{TiO}_{2}$ framework and stabilising the anatase phase.

\section{Acknowledgements}

The authors wish to acknowledge financial support from the U.S. Ireland R\&D Partnership Initiative, Science Foundation Ireland (SFI-grant number 10/US/I1822 (T)). We would also like to acknowledge Damian Synnott for his intellectual contributions toward this study.

\section{Notes and references}

[1] S. Banerjee, S.C. Pillai, P. Falaras, K.E. O’Shea, J.A. Byrne, D.D. Dionysiou, New Insights into the Mechanism of Visible Light Photocatalysis, J. Phys. Chem. Lett. 5 (2014) 2543-2554. doi:10.1021/jz501030x.

[2] V. Etacheri, M.K. Seery, S.J. Hinder, S.C. Pillai, Oxygen Rich Titania: A Dopant Free, High Temperature Stable, and Visible-Light Active Anatase Photocatalyst, Adv. Funct. Mater. 21 (2011) 3744-3752. doi:10.1002/adfm.201100301.
[3] E. Allain, S. Besson, C. Durand, M. Moreau, T. Gacoin, J.-P. Boilot, Transparent Mesoporous Nanocomposite Films for Self-Cleaning Applications, Adv. Funct. Mater. 17 (2007) 549-554. doi:10.1002/adfm.200600197.

[4] R. O’Hayre, M. Nanu, J. Schoonman, A. Goossens, Q. Wang, M. Grätzel, The Influence of TiO2 Particle Size in TiO2/CuInS2 Nanocomposite Solar Cells, Adv. Funct. Mater. 16 (2006) 1566-1576. doi:10.1002/adfm.200500647.

[5] J. Schneider, M. Matsuoka, M. Takeuchi, J. Zhang, Y. Horiuchi, M. Anpo, et al., Understanding TiO 2 Photocatalysis : Mechanisms and Materials, Chem. Rev. 114 (2014) 9919-9986. doi:10.1021/cr5001892.

[6] A. Ibhadon, P. Fitzpatrick, Heterogeneous Photocatalysis: Recent Advances and Applications, Catalysts. 3 (2013) 189-218. doi:10.3390/catal3010189.

[7] S.-Y. Lee, S.-J. Park, TiO2 photocatalyst for water treatment applications, J. Ind. Eng. Chem. 19 (2013) 1761-1769. doi:10.1016/j.jiec.2013.07.012.

[8] L. Zhang, H.H. Mohamed, R. Dillert, D. Bahnemann, Kinetics and mechanisms of charge transfer processes in photocatalytic systems: A review, J. Photochem. Photobiol. C Photochem. Rev. 13 (2012) 263-276. doi:10.1016/j.jphotochemrev.2012.07.002.

[9] R. Fateh, A.A. Ismail, R. Dillert, D.W. Bahnemann, Highly Active Crystalline Mesoporous TiO 2 Films Coated onto Polycarbonate Substrates for SelfCleaning Applications, J. Phys. Chem. C. 115 (2011) 10405-10411. doi:10.1021/jp200892z.

[10] J.W. MacFarlane, H.F. Jenkinson, T.B. Scott, Sterilization of microorganisms on jet spray formed titanium dioxide surfaces, Appl. Catal. B Environ. 106 (2011) 181-185. doi:10.1016/j.apcatb.2011.05.023.

[11] K. Hashimoto, H. Irie, A. Fujishima, TiO 2 Photocatalysis: A Historical Overview and Future Prospects, Jpn. J. Appl. Phys. 44 (2005) 8269-8285. doi:10.1143/JJAP.44.8269.

[12] T. Tatsuma, W. Kubo, A. Fujishima, Patterning of solid surfaces by photocatalytic lithography based on the remote oxidation effect of TiO2, Langmuir. 18 (2002) 9632-9634. doi:10.1021/la026246u. 
[13] Z. Zsilák, E. Szabó-Bárdos, O. Fónagy, O. Horváth, K. Horváth, P. Hajós, Degradation of benzenesulfonate by heterogeneous photocatalysis combined with ozonation, Catal. Today. 230 (2014) 55-60. doi:10.1016/j.cattod.2013.10.039.

[14] V. Vamathevan, R. Amal, D. Beydoun, G. Low, S. McEvoy, Photocatalytic oxidation of organics in water using pure and silver-modified titanium dioxide particles, J. Photochem. Photobiol. A Chem. 148 (2002) 233-245. doi:10.1016/S10106030(02)00049-7.

[15] R. Fagan, D.E. Mccormack, D.D. Dionysiou, S.C. Pillai, A review of solar and visible light active $\mathrm{TiO}$ 2 photocatalysis for treating bacteria , cyanotoxins and contaminants of emerging concern, Mater. Sci. Semicond. Process. 42, (2015) 2-14. doi:10.1016/j.mssp.2015.07.052.

[16] Y. Ohko, S. Saitoh, T. Tatsuma, A. Fujishima, Photoelectrochemical Anticorrosion and SelfCleaning Effects of a TiO2 Coating for Type 304 Stainless Steel, J. Electrochem. Soc. 148 (2001) B24. doi:10.1149/1.1339030.

[17] M. Pelaez, N.T. Nolan, S.C. Pillai, M.K. Seery, P. Falaras, A.G. Kontos, et al., A review on the visible light active titanium dioxide photocatalysts for environmental applications, Appl. Catal. B Environ. 125 (2012) 331-349.

doi:10.1016/j.apcatb.2012.05.036.

[18] D.A. Keane, K.G. McGuigan, P.F. Ibáñez, M.I. PoloLópez, J.A. Byrne, P.S.M. Dunlop, et al., Solar photocatalysis for water disinfection: materials and reactor design, Catal. Sci. Technol. 4 (2014) 12111217. doi:10.1039/c4cy00006d.

[19] K. Kobayakawa, Y. Murakami, Y. Sato, Visible-light active $\mathrm{N}$-doped $\mathrm{TiO} 2$ prepared by heating of titanium hydroxide and urea, J. Photochem. Photobiol. A Chem. 170 (2005) 177-179. doi:10.1016/j.jphotochem.2004.07.010.

[20] E. Bae, W. Choi, J. Park, H.S. Shin, S. Bin Kim, J.S. Lee, Effects of Surface Anchoring Groups (Carboxylate vs Phosphonate) in RutheniumComplex-Sensitized TiO 2 on Visible Light Reactivity in Aqueous Suspensions, J. Phys. Chem. B. 108 (2004) 14093-14101. doi:10.1021/jp047777p.

[21] C. Minero, G. Mariella, V. Maurino, E. Pelizzetti, Photocatalytic Transformation of Organic
Compounds in the Presence of Inorganic Anions. 1. Hydroxyl-Mediated and Direct Electron-Transfer Reactions of Phenol on a Titanium Dioxide-Fluoride System, Langmuir. 16 (2000) 2632-2641. doi:10.1021/la9903301.

[22] H. Park, Y. Park, W. Kim, W. Choi, Surface modification of $\mathrm{TiO} 2$ photocatalyst for environmental applications, J. Photochem. Photobiol. C Photochem. Rev. 15 (2013) 1-20. doi:10.1016/j.jphotochemrev.2012.10.001.

[23] W. Choi, Pure and modified TiO2 photocatalysts and their environmental applications, Catal. Surv. from Asia. 10 (2006) 16-28. doi:10.1007/s10563-0069000-2.

[24] G.-S. Shao, T.-Y. Ma, X.-J. Zhang, T.-Z. Ren, Z.-Y. Yuan, Phosphorus and nitrogen co-doped titania photocatalysts with a hierarchical meso/macroporous structure, J. Mater. Sci. 44 (2009) 6754-6763. doi:10.1007/s10853-009-3628-z.

[25] S. Sakthivel, H. Kisch, Daylight Photocatalysis by Carbon-Modified Titanium Dioxide, Angew. Chemie - Int. Ed. 42 (2003) 4908-4911. doi:10.1002/anie.200351577.

[26] M. Kang, The superhydrophilicity of Al-TiO2 nanometer sized material synthesized using a solvothermal method, Mater. Lett. 59 (2005) 31223127. doi:10.1016/j.matlet.2005.05.032.

[27] S. Sakthivel, M. Janczarek, H. Kisch, Visible light activity and photoelectrochemical properties of nitrogen-doped TiO2, J. Phys. Chem. B. 108 (2004) 19384-19387. doi:10.1021/jp046857q.

[28] S. Livraghi, M. Pelaez, J. Biedrzycki, I. Corazzari, E. Giamello, D.D. Dionysiou, Influence of the chemical synthesis on the physicochemical properties of $\mathrm{N}$ TiO2 nanoparticles, Catal. Today. 209 (2013) 54-59. doi:10.1016/j.cattod.2012.12.020.

[29] Y. Aita, M. Komatsu, S. Yin, T. Sato, Phasecompositional control and visible light photocatalytic activity of nitrogen-doped titania via solvothermal process, J. Solid State Chem. 177 (2004) 3235-3238. doi:10.1016/j.jssc.2004.04.048.

[30] M.V. Dozzi, E. Selli, Doping TiO2 with p-block elements: Effects on photocatalytic activity, J. Photochem. Photobiol. C Photochem. Rev. 14 (2013) 13-28. doi:10.1016/j.jphotochemrev.2012.09.002. 
[39] P. Periyat, D.E. McCormack, J. Colreavy, S.C. Pillai, S.J. Hinder, Improved High-Temperature Stability and Sun- Light-Driven Photocatalytic Activity of Sulfur- Doped Anatase TiO2 Improved HighTemperature Stability and Sun-Light-Driven Photocatalytic Activity of, J. Phys. Chem. 112 (2008) 7644-7652.

[32] T. Umebayashi, T. Yamaki, H. Itoh, K. Asai, Band gap narrowing of titanium dioxide by sulfur doping, Appl. Phys. Lett. 81 (2002) 454. doi:10.1063/1.1493647.

[33] R. Zheng, Y. Guo, C. Jin, J. Xie, Y. Zhu, Y. Xie, Novel thermally stable phosphorus-doped TiO2 photocatalyst synthesized by hydrolysis of TiCl4, J. Mol. Catal. A Chem. 319 (2010) 46-51. doi:10.1016/j.molcata.2009.11.019.

[40] Y. Lv, L. Yu, H. Huang, H. Liu, Y. Feng, Preparation of F-doped titania nanoparticles with a highly thermally stable anatase phase by alcoholysis of TiCl4, Appl. Surf. Sci. 255 (2009) 9548-9552. doi:10.1016/j.apsusc.2009.07.098.

[41] S.C. Padmanabhan, S.C. Pillai, J. Colreavy, S. Balakrishnan, D.E. McCormack, T.S. Perova, et al., A simple sol - Gel processing for the development of high-temperature stable photoactive anatase titania, Chem. Mater. 19 (2007) 4474-4481. doi:10.1021/cm070980n.

[34] S. Guo, S. Han, M. Haifeng, C. Zeng, Y. Sun, B. Chi, et al., Synthesis of phosphorus-doped titania with mesoporous structure and excellent photocatalytic activity, Mater. Res. Bull. 48 (2013) 3032-3036. doi:10.1016/j.materresbull.2013.04.056.

[35] D. Li, H. Haneda, S. Hishita, N. Ohashi, N.K. Labhsetwar, Fluorine-doped TiO2 powders prepared by spray pyrolysis and their improved photocatalytic activity for decomposition of gas-phase acetaldehyde, J. Fluor. Chem. 126 (2005) 69-77. doi:10.1016/j.jfluchem.2004.10.044.

[36] Y. Wu, M. Xing, B. Tian, J. Zhang, F. Chen, Preparation of nitrogen and fluorine co-doped mesoporous $\mathrm{TiO} 2$ microsphere and photodegradation of acid orange 7 under visible light, Chem. Eng. J. 162 (2010) 710-717. doi:10.1016/j.cej.2010.06.030.

[37] S.C. Padmanabhan, S. Pillai, J. Colreavy, S. Balakrishman, D.E. McCormack, T.S. Perova, et al., A Simple Sol-Gel Processing for the Development of High-Temperature Stable Photoactive Anatase Titania A Simple Sol-Gel Processing for the Development of High-Temperature Stable Photoactive Anatase Titania, Chem. Mater. 19 (2007) 4474-4481.

[42] H.-F. Yu, Photocatalytic abilities of gel-derived Pdoped TiO2, J. Phys. Chem. Solids. 68 (2007) 600607. doi:10.1016/j.jpcs.2007.01.050.

[43] W. Schreiner, R. Jenkins, Profile fitting for quantitative analysis in $\mathrm{x}$-ray powder diffraction, Adv. X-Ray Anal. 26 (1983) 141-147. https://apps.webofknowledge.com/full_record.do?pr oduct=UA\&search_mode $=$ GeneralSearch\&qid $=10 \&$ $\mathrm{SID}=\mathrm{Z111}$ MUoxmEYZMNjFjMG\&page $=1 \& \mathrm{doc}=5$ (accessed June 2, 2015).

[44] R.A. Spurr, H. Myers, Quantitative Analysis of Anatase-Rutile Mixtures with an X-Ray Diffractometer, Anal. Chem. 29 (1957) 760-762. doi:10.1021/ac60125a006.

[45] X. Li, H. Zhang, X. Zheng, Z. Yin, L. Wei, Visible light responsive N-F-codoped TiO2 photocatalysts for the degradation of 4-chlorophenol, J. Environ. Sci. 23 (2011) 1919-1924. doi:10.1016/S10010742(10)60656-0.

[46] F. Peng, L. Cai, H. Yu, H. Wang, J. Yang, Synthesis and characterization of substitutional and interstitial nitrogen-doped titanium dioxides with visible light photocatalytic activity, J. Solid State Chem. 181 (2008) 130-136. doi:10.1016/j.jssc.2007.11.012.

[38] V. Etacheri, G. Michlits, M.K. Seery, S.J. Hinder, S.C. Pillai, A highly efficient TiO2-xCx nanoheterojunction photocatalyst for visible light induced antibacterial applications, ACS Appl. Mater. Interfaces. 5 (2013) 1663-1672. doi:10.1021/am302676a.

[47] R. Nakamura, T. Tanaka, Y. Nakato, Mechanism for Visible Light Responses in Anodic Photocurrents at N-Doped TiO 2 Film Electrodes, J. Phys. Chem. B. 108 (2004) 10617-10620. doi:10.1021/jp048112q. 
[48] S. Baunack, S. Oswald, D. Scharnweber, Depth distribution and bonding states of phosphorus implanted in titanium investigated by AES, XPS and SIMS, Surf. Interface Anal. 26 (1998) 471-479. doi:10.1002/(SICI)10969918(19980515)26:63.0.CO;2-S.

[49] N.T. Nolan, M.K. Seery, S.J. Hinder, L.F. Healy, S.C. Pillai, A systematic study of the effect of silver on the chelation of formic acid to a titanium precursor and the resulting effect on the anatase to rutile transformation of TiO2, J. Phys. Chem. C. 114 (2010) 13026-13034. doi:10.1021/jp1016054.

[50] C.E. Bamberger, G.M. Begun, Synthesis and characterization of titanium phosphates, TiP2O7 AND (TiO)2P2O7, J. Less Common Met. 134 (1987) 201-206. doi:10.1016/0022-5088(87)90558-3.

[51] N.T. Nolan, D.W. Synnott, M.K. Seery, S.J. Hinder, A. Van Wassenhoven, S.C. Pillai, Effect of N-doping on the photocatalytic activity of sol-gel $\mathrm{TiO}(2)$., J. Hazard. Mater. 211-212 (2012) 88-94. doi:10.1016/j.jhazmat.2011.08.074.

[52] T. Information, AEROXIDE $\AA$, AERODISP ${ }^{\circledR}$ and AEROPERL ${ }^{\circledR}$ Titanium Dioxide as Photocatalyst, (2015).

[53] S. Livraghi, K. Elghniji, A.M. Czoska, M.C. Paganini, E. Giamello, M. Ksibi, Journal of Photochemistry and Photobiology A : Chemistry Nitrogen-doped and nitrogen - fluorine-codoped titanium dioxide . Nature and concentration of the photoactive species and their role in determining the photocatalytic activity under visible light, Photochem. Photobiol. 205 (2009) 93-97. doi:10.1016/j.jphotochem.2009.04.010.

[54] V. Etacheri, M.K. Seery, S.J. Hinder, S.C. Pillai, Nanostructured Ti 1 - x S x O 2 - y N y Heterojunctions for Efficient Visible-, 51 (2012)
[55] S.Y. Choi, M. Mamak, N. Coombs, N. Chopra, G.A Ozin, Thermally Stable Two-Dimensional Hexagonal Mesoporous Nanocrystalline Anatase, Meso-nc-TiO2: Bulk and Crack-Free Thin Film Morphologies, Adv. Funct. Mater. 14 (2004) 335344. doi:10.1002/adfm.200305039.

[56] H. Zhang, J.F. Banfield, Thermodynamic analysis of phase stability of nanocrystalline titania, J. Mater. Chem. 8 (1998) 2073-2076. doi:10.1039/a802619j.

[57] A.S. Barnard, P. Zapol, Predicting the Energetics, Phase Stability, and Morphology Evolution of Faceted and Spherical Anatase Nanocrystals, J. Phys. Chem. B. 108 (2004) 18435-18440. doi:10.1021/jp0472459.

[58] M. Anpo, T. Shima, S. Kodama, Y. Kubokawa, Photocatalytic hydrogenation of propyne with water on small-particle titania: size quantization effects and reaction intermediates, J. Phys. Chem. 91 (1987) 4305-4310. doi:10.1021/j100300a021.

[59] M.N. Ghazzal, H. Kebaili , M. Joseph, D.P. Debecker, P. Eloy, J. De Coninck, E.M. Gaigneaux Photocatalytic degradation of Rhodamine 6G on mesoporous titania films: Combined effect of texture and dye aggregation forms, Applied Catalysis B: Environmental 115-116 (2012) 276-284; doi doi:10.1016/j.apcatb.2011.12.016

[60] V. Etacheri, C. Di Valentin, J. Schneider, D. Bahnemann, S. C. Pillai Visible-light activation of $\mathrm{TiO} 2$ photocatalysts: Advances in theory and experiments, Journal of Photochemistry and Photobiology C: Photochemistry Reviews 25 (2015) 1-29; doi:10.1016/j.jphotochemrev.2015.08.003 


\section{Supplementary Information}

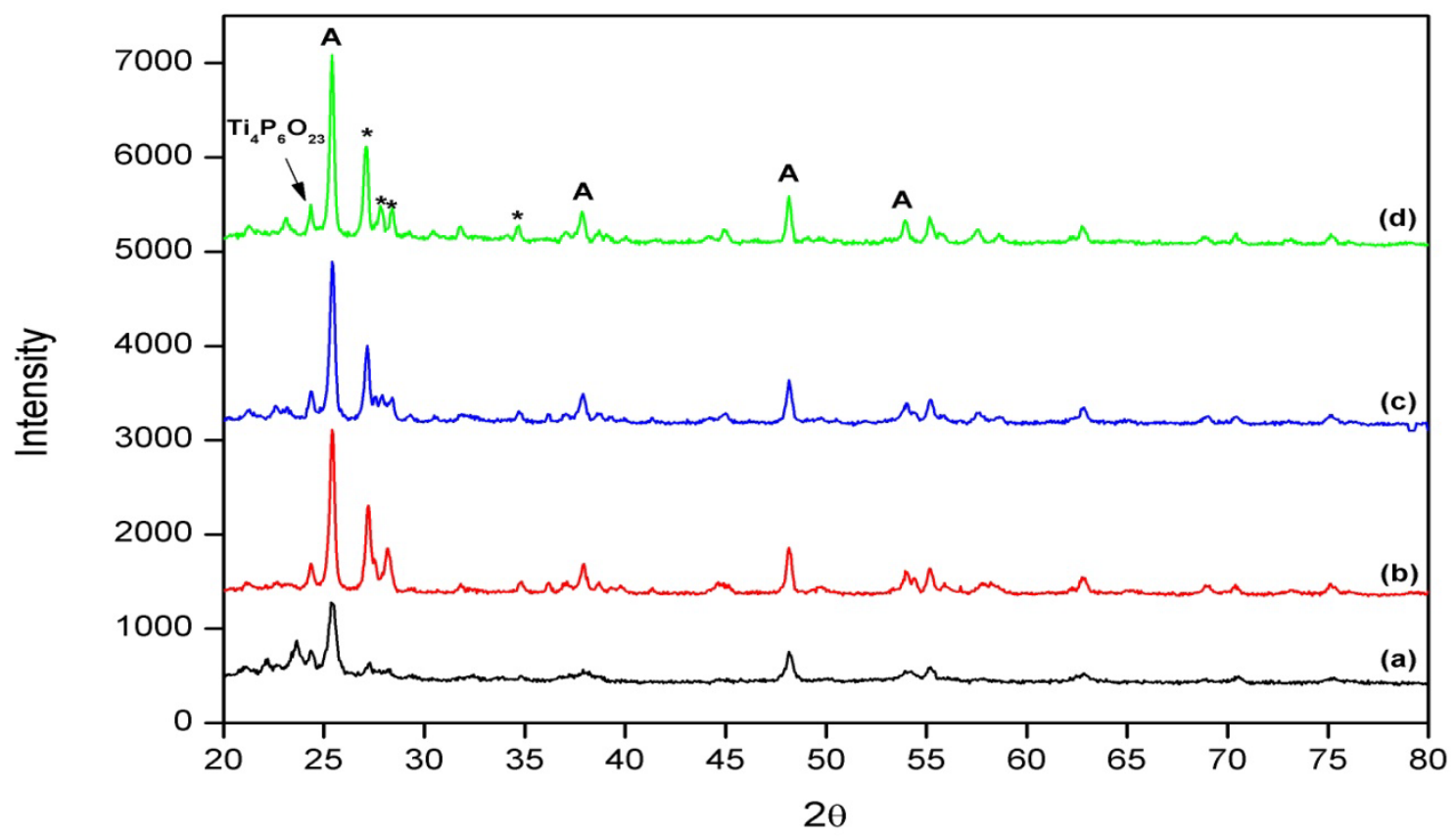

Figure S.1. Comparison XRD analysis of sample NFP-0.5, Method A, prepared at varying temperatures.. (a) $600{ }^{\circ} \mathrm{C}$, (b) $700^{\circ} \mathrm{C}$, (c) $800{ }^{\circ} \mathrm{C}$ and (d) $1000^{\circ} \mathrm{C}$.

* indicates the presence of $(\mathrm{TiO})_{2} \mathrm{P}_{2} \mathrm{O}_{7}$ and $\mathrm{A}=$ Aanatase

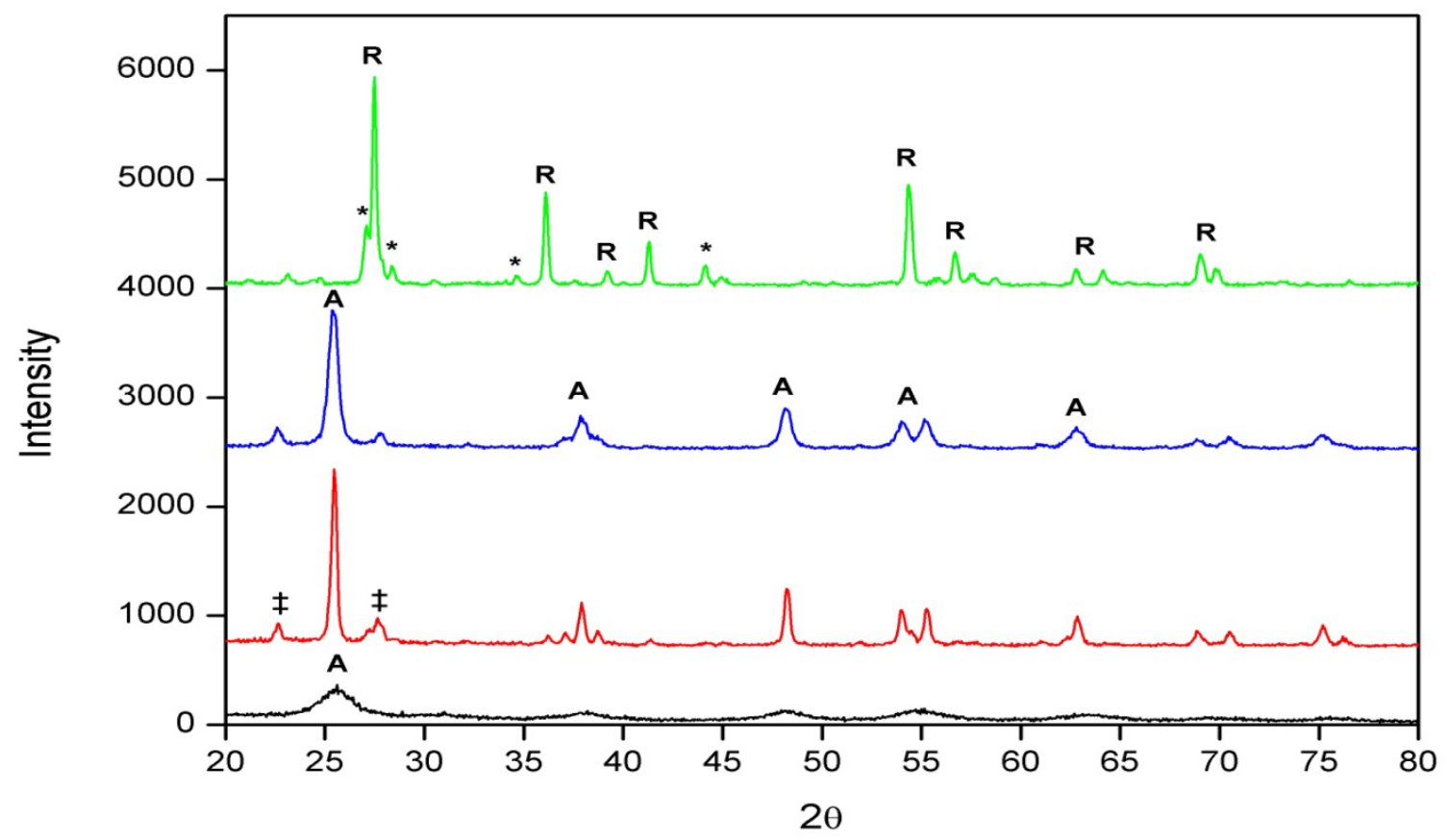

Figure S.2. Comparison XRD analysis of sample NFP-0.5, Method B, prepared at varying temperatures.. (a) $600{ }^{\circ} \mathrm{C}$, (b) $700^{\circ} \mathrm{C}$, (c) $800^{\circ} \mathrm{C}$ and (d) $1000^{\circ} \mathrm{C}$.

* indicates the presence of $(\mathrm{TiO})_{2} \mathrm{P}_{2} \mathrm{O}_{7}$, $¥$ indicates the presence of $\mathrm{Ti}_{4} \mathrm{P}_{6} \mathrm{O}_{23}$, and $\mathrm{A}=$ Aanatase; $\mathrm{R}=$ Rutile 


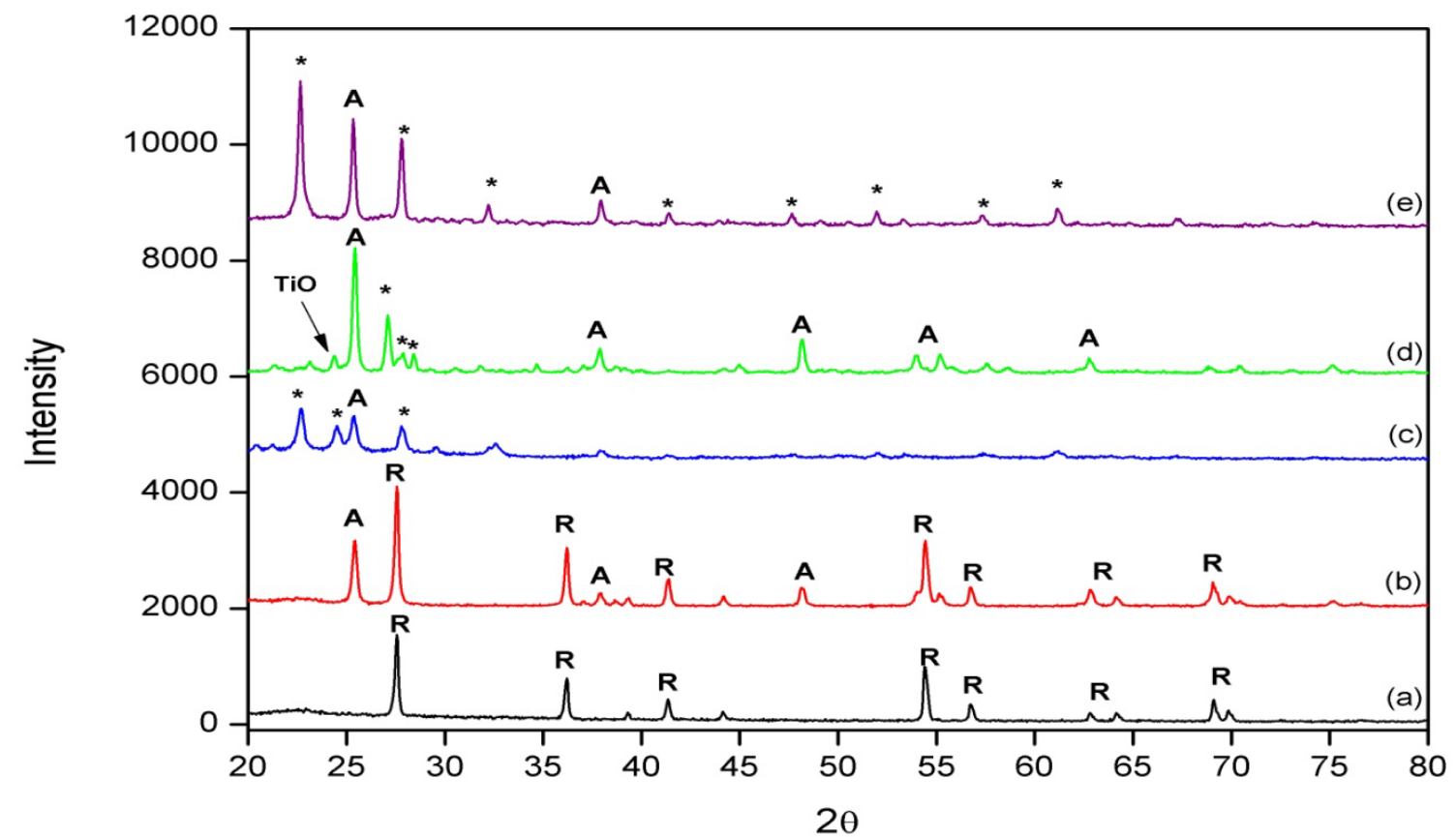

Figure S.3. Comparison XRD of different doped $\mathrm{TiO}_{2}$ systems calcined at $900{ }^{\circ} \mathrm{C}$. (a) N-doped $\mathrm{TiO}_{2}$, (b) F-doped $\mathrm{TiO}_{2}$ (c) NFP: $\mathrm{TiO}_{2}$ method A (2:1), (d) NFP: $\mathrm{TiO}_{2}$ method A (0.5:1) and (e) P-doped $\mathrm{TiO}_{2}$.

* denotes peaks identified as titanium oxide phosphate $\left((\mathrm{TiO})_{2} \mathrm{P}_{2} \mathrm{O}_{7}\right), A=A a n a t a s e ; R=$ Rutile

(a)

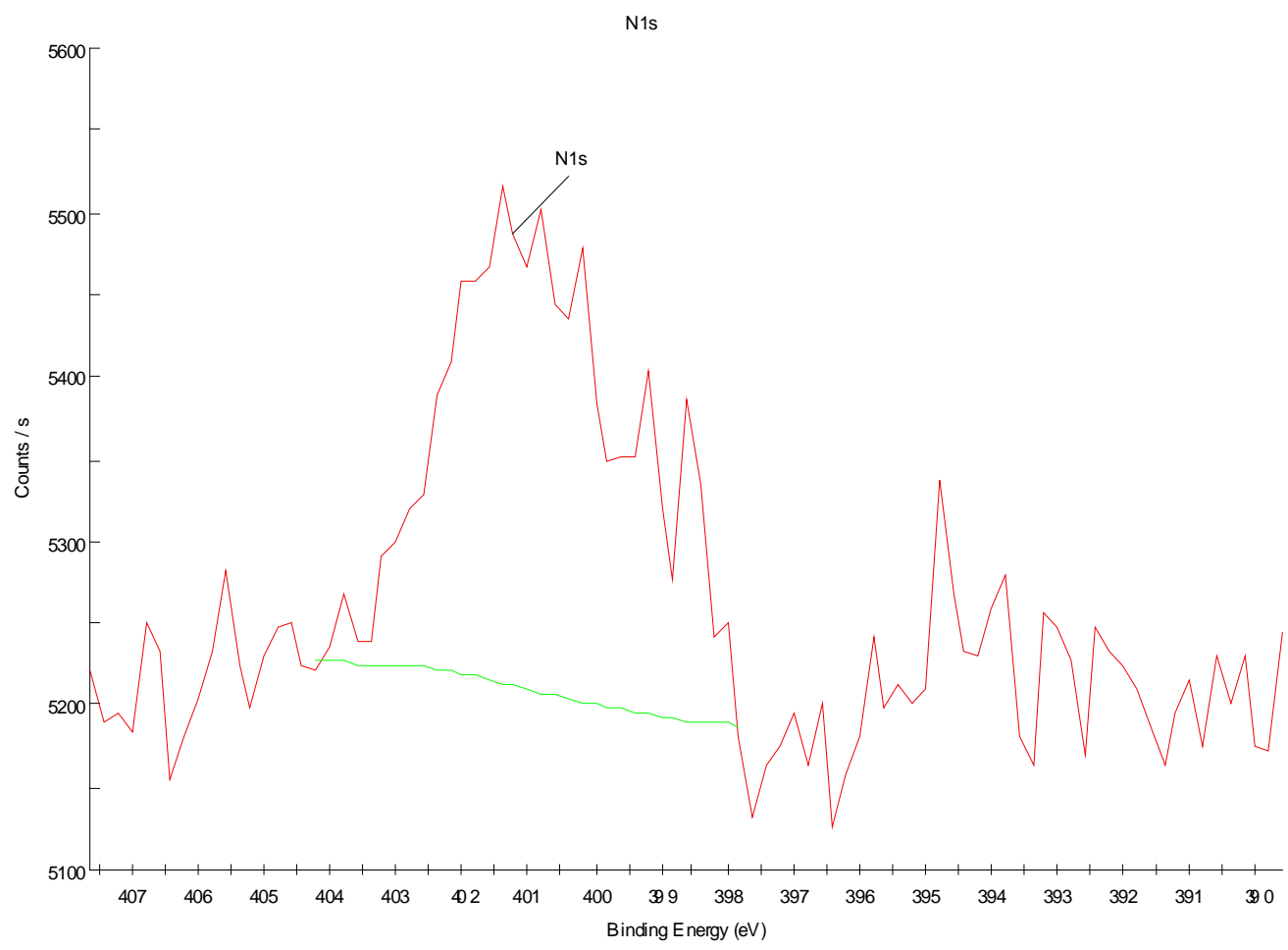

(b) 


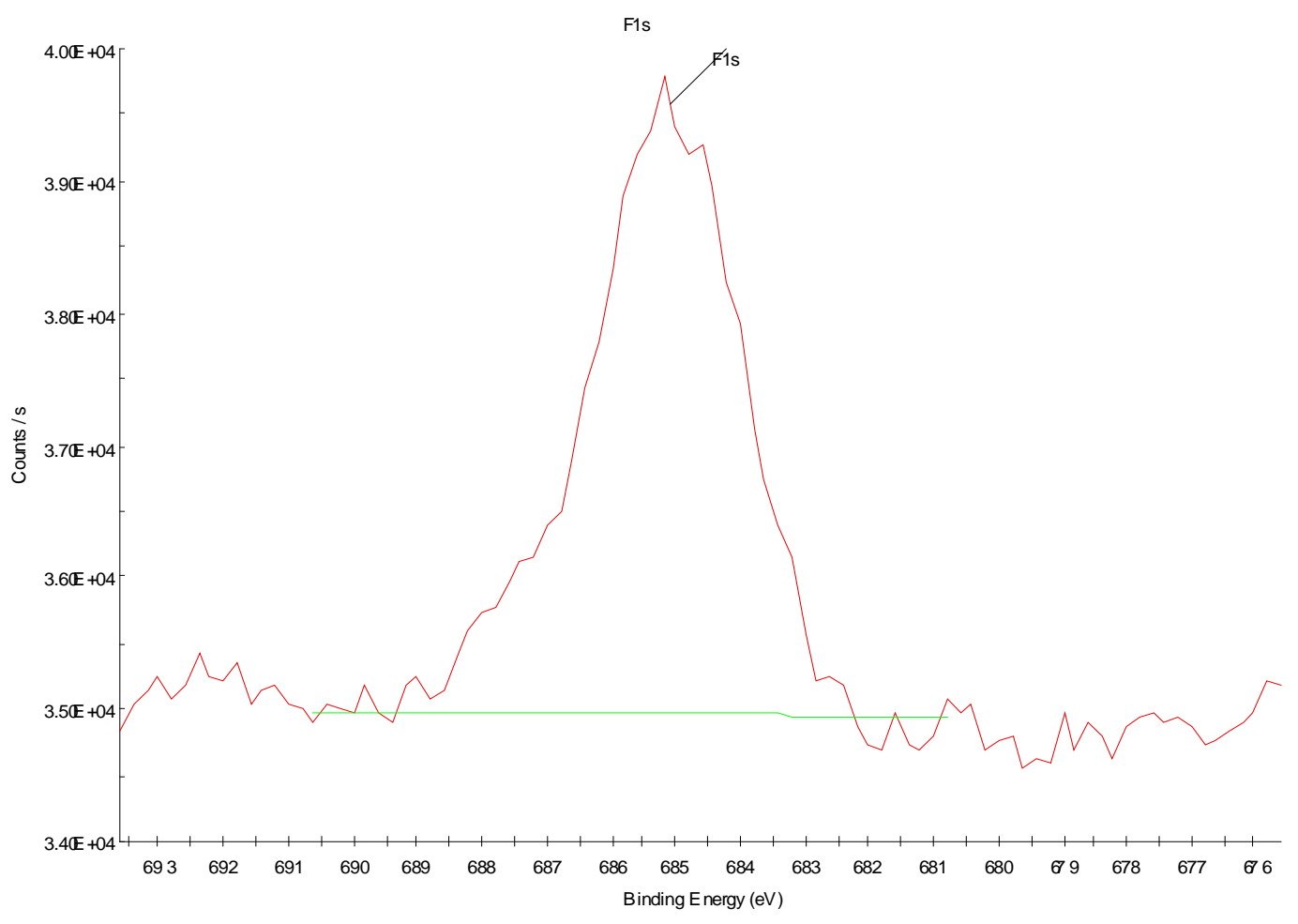

(c)

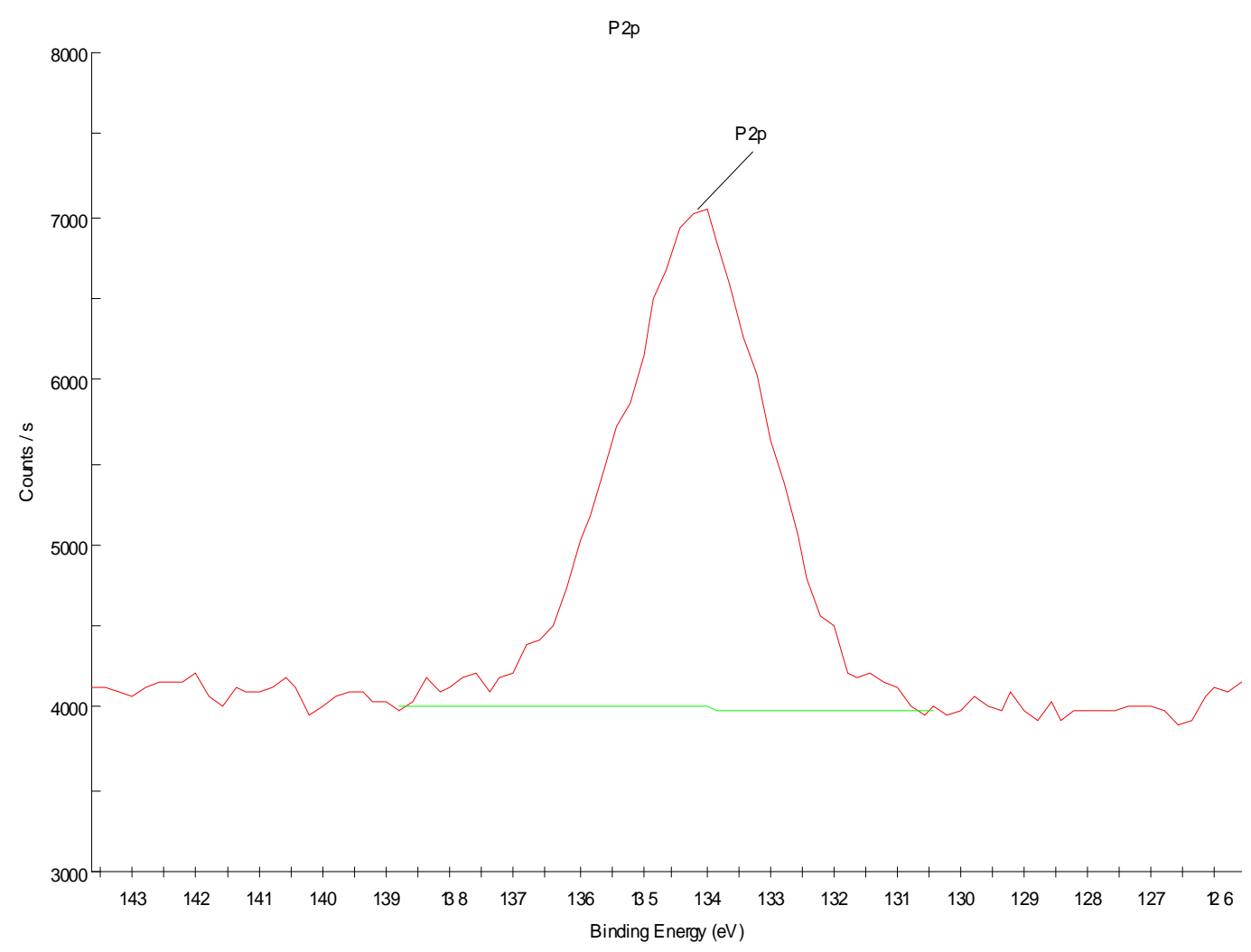

Figure S.4. XPS spectra of sample NFP-0.5 (method A) calcined at $500{ }^{\circ} \mathrm{C}$. (a) Nitrogen (N 1s), (b) fluorine (F 1s) and (c) phosphorus (P 2p) 


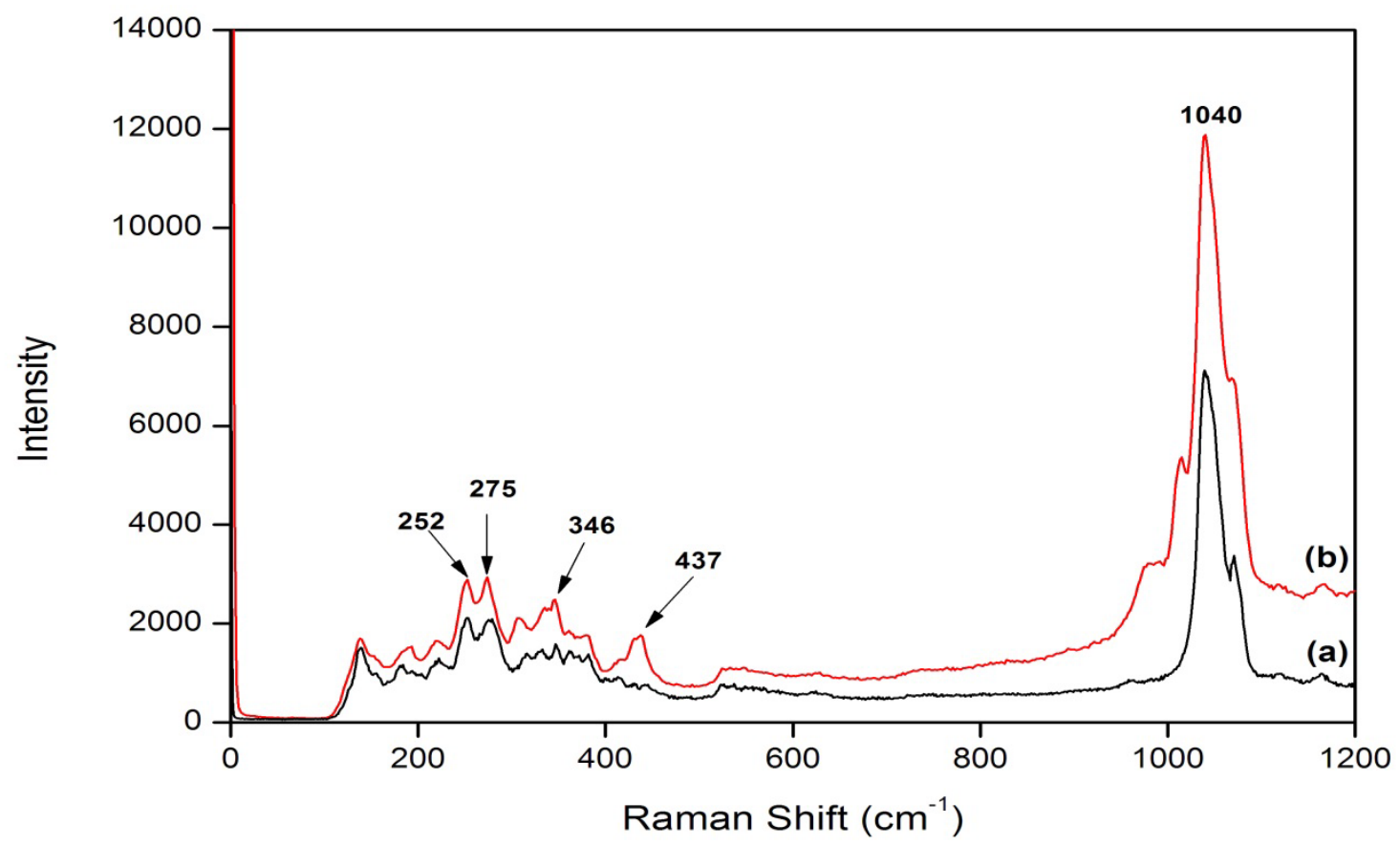

Figure S.5. Raman spectra of samples calcined at $900{ }^{\circ} \mathrm{C}$, comparing doping systems of titanium dioxide. (a) method A prepared NFP doped $\mathrm{TiO}_{2}$ (in a ratio of 2:1), (b) P- doped $\mathrm{TiO}_{2}$ (in a ratio of 2:1).

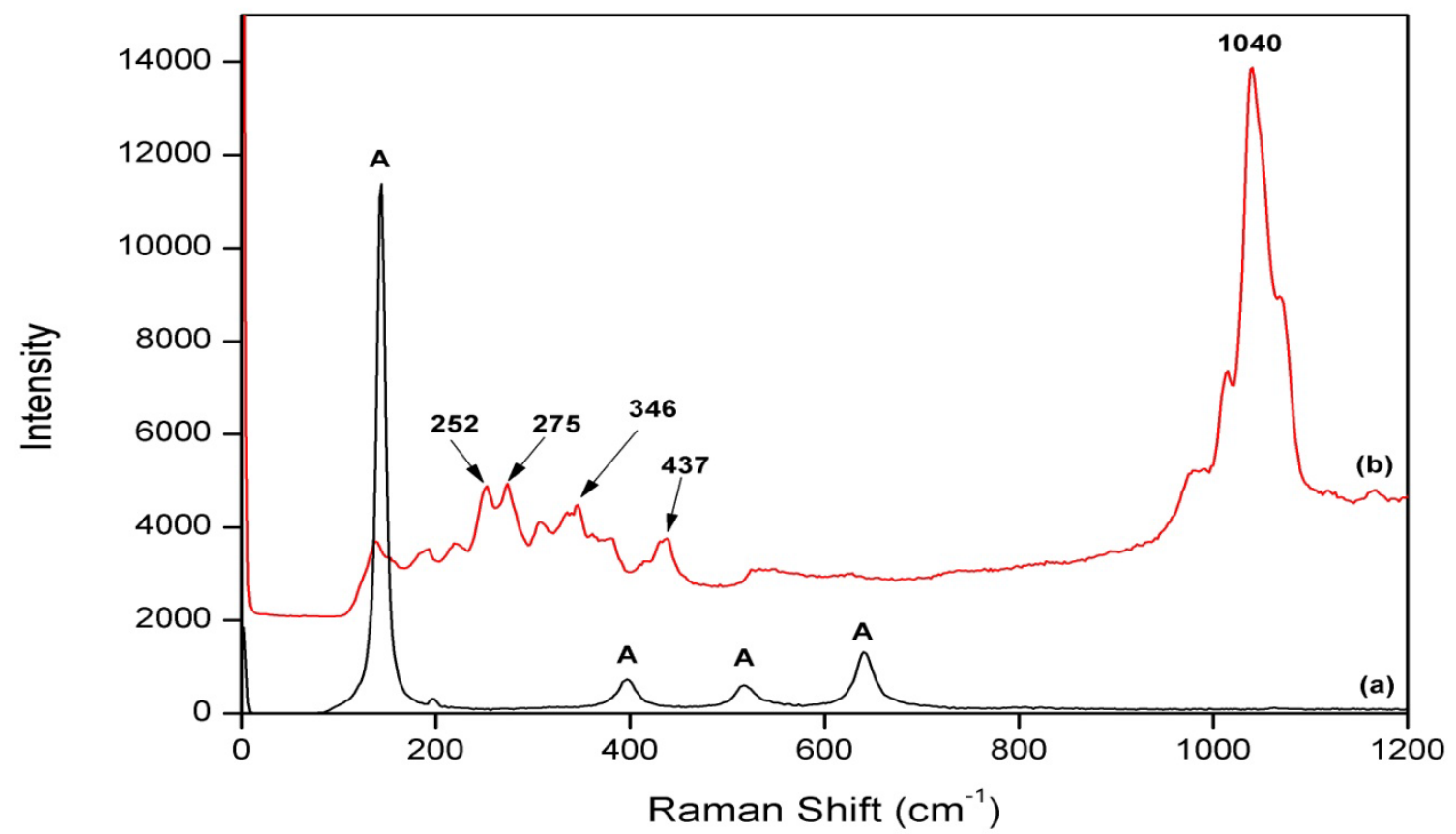

Figure S.6. Raman spectra of samples calcined at $900{ }^{\circ} \mathrm{C}$, comparing doping systems of titanium dioxide. (a) method A prepared NFP doped $\mathrm{TiO}_{2}$ (in a ratio of 2:1), (b) NF- doped $\mathrm{TiO}_{2}$ (in a ratio of 2:1). A=Aanatase 
Table S.1 Particle size $(\mathrm{nm})$ calculated for samples over a range of calcination temperatures

\begin{tabular}{|c|c|c|c|c|c|}
\hline \multirow[t]{3}{*}{ Sample Name } & \multirow{3}{*}{$\begin{array}{l}\text { Temp. of calcination } \\
\left({ }^{\circ} \mathrm{C}\right)\end{array}$} & \multicolumn{4}{|c|}{ Particle size } \\
\hline & & \multicolumn{2}{|c|}{ Method A } & \multicolumn{2}{|c|}{ Method B } \\
\hline & & Anatase & Rutile & Anatase & Rutile \\
\hline NFP-0.5 & 400 & 0 & 0 & 0 & 0 \\
\hline NFP-0.5 & 500 & 0 & 0 & 3.9 & 0 \\
\hline NFP-0.5 & 600 & 19.4 & 0 & 3.9 & 0 \\
\hline NFP-0.5 & 700 & 25.3 & 0 & 27.8 & 0 \\
\hline NFP-0.5 & 800 & 24.0 & 0 & 15.8 & 0 \\
\hline NFP-0.5 & 900 & 27.5 & 0 & 0 & 30.8 \\
\hline NFP-0.5 & 1000 & 29.5 & 0 & 0 & 33.4 \\
\hline NFP-0.5 & 1100 & 40.7 & 0 & 0 & 41.1 \\
\hline
\end{tabular}

Table S.2. Rates of reactions for Rhodamine $6 \mathrm{G}$ decomposition

\begin{tabular}{|c|c|c|c|c|c|c|c|c|c|}
\hline \multirow[t]{2}{*}{$\begin{array}{l}\text { Sample } \\
\text { name }\end{array}$} & \multirow[t]{2}{*}{$\begin{array}{l}\text { Temp } \\
\left({ }^{\circ} \mathrm{C}\right)\end{array}$} & \multicolumn{4}{|c|}{$\begin{array}{l}\text { Rate of reaction }\left(\mathrm{min}^{-1}\right) \text { Average values } \\
\text { Average values }\end{array}$} & \multirow[t]{2}{*}{$\begin{array}{l}\text { Commercial } \\
\text { Standards }\end{array}$} & \multirow[t]{2}{*}{$\begin{array}{l}\text { Temp } \\
\left({ }^{\circ} \mathrm{C}\right)\end{array}$} & \multirow{2}{*}{$\begin{array}{l}\text { Average values } \\
\text { Rate constant } \\
\text { (k) }\left(\min ^{-1}\right)\end{array}$} & \multirow{2}{*}{$\begin{array}{l}\text { Standard } \\
\text { deviation } \\
\text { Rate constant } \\
\text { (k) }\left(\mathrm{min}^{-1}\right)\end{array}$} \\
\hline & & $\begin{array}{l}\text { Method } \\
\text { A }\end{array}$ & $\begin{array}{l}\text { Standard } \\
\text { deviation }\end{array}$ & $\begin{array}{c}\text { Method } \\
\text { B }\end{array}$ & $\begin{array}{l}\text { Standard } \\
\text { deviation }\end{array}$ & & & & \\
\hline NFP- & 500 & 0.019 & 0.005 & 0.054 & 0.003 & Degussa & - & 0.202 & 0.001 \\
\hline NFP- & 600 & 0.038 & 0.005 & 0.065 & 0.004 & Degussa & 500 & 0.087 & 0.013 \\
\hline NFP- & 700 & 0.055 & 0.010 & 0.011 & 0.003 & Degussa & 900 & 0.040 & 0.010 \\
\hline NFP- & 800 & 0.063 & 0.003 & 0.020 & 0.001 & Degussa & 1000 & 0.011 & 0.003 \\
\hline NFP- & 900 & 0.070 & 0.006 & 0.006 & 0.005 & Degussa & 1100 & 0.031 & 0.001 \\
\hline NFP- & 1000 & 0.057 & 0.005 & 0.003 & 0.002 & VLP7000 & - & 0.027 & 0.013 \\
\hline \multirow[t]{4}{*}{ NFP- } & 1100 & 0.042 & 0.001 & 0.005 & 0.002 & VLP7000 & 500 & 0.057 & 0.006 \\
\hline & & & & & & VLP7000 & 900 & 0.019 & 0.003 \\
\hline & & & & & & VLP7000 & 1000 & 0.021 & 0.013 \\
\hline & & & & & & VLP7000 & 1100 & 0.002 & 0.001 \\
\hline
\end{tabular}


